$\mathrm{AD} / \mathrm{AP} / \mathrm{Tech}$. Note No. 6

Accelerator Development Department

BROOKHAVEN NATIONAL LABORATORY

Associated Universities, Inc.

Upton, New York 11973

Accelerator Physics Technical Note. No. 6

NONLINEAR EFFECTS AND CHROMATICITY STUDIES FOR THE AGS BOOSTER

Zohreh Parsa

June 1987 
BROOKHAVEN NATIONAL IABORATORY

UPTON, NEW YORK 11973

NONLINEAR EFFECTS AND CHROMATICITY STUDIES FOR THE AGS BOOSTER

ZOHREH PARSA

This is a summary of the presentation at the April and May 1987 (Interdepartmental) Accelerator Physics seminarsat the Physics Department. It includes a theoretical overview of our formalism. and some results of our chromaticity studies for the operation of the Booster. Comparison of our

-- analytic results and those obtained from progrma HARMON and tracking programs PATRICIA (F. DeII) and ORBIT (G. Parzen) are also included. 
I. Theory (an overview)

II. AGS Booster 
II. THEORY

The Hamiltonian of a dynamical system can be expressed by

$$
\mathrm{H}=\frac{2 \pi}{\mathrm{C}} \nu_{\mathrm{x}}^{0} \mathrm{~J}_{\mathrm{x}}+\frac{2 \pi}{\mathrm{C}} \nu_{z}^{0} \mathrm{~J}_{z}+V\left(\mathrm{~J}_{\mathrm{x}}, \mathrm{J}_{z}, \phi_{\mathrm{x}}, \phi_{z}, \mathrm{~s}\right)
$$

where $\left(J x,{ }^{\phi}\right)$ and $\left(J z,{ }^{\phi}\right)$ are the action - angle variables; $v_{x}^{0}$ and $v_{z}^{0}$ are the linear tunes; $C$ is the circumference of the machine and $V$ (the perturtiong potential) is periodic in ${ }^{\phi} \mathrm{x},{ }^{\phi} \mathrm{z}$, and $\mathrm{s}$.

Expanding $V$ in a fourier series about ${ }^{\phi} x,{ }^{\phi} z$, and $s$, we find a term in which the argument of the sine and cosine term varies the slowest with s. Since this term gives the greatest contribution to the dynamics of the system, we only consider this term and neglect the others. This leads to the following Hamiltonian:

$H \cong \frac{2 \pi}{C} \nu_{x}^{\circ} J_{x}+\frac{2 \pi}{C} \nu_{z}^{\circ} J_{z}+I\left(J_{x}, J_{z}\right)$

$$
+\frac{I}{C} A\left(J_{x}, J_{z}\right) \cos \left(n_{x} \phi x+n_{z} \phi_{z}-\frac{2 \pi}{C} p s+\theta\right)
$$

Where $A(J x, J z)$ is the Hamiltonian Resonance strength, $\theta$ is the constant phase and $I(J x, J z)$ is the term that causes the perturtation of tune, $p, n_{x}$ and $n_{z}$ defines a given resonance.

To find the resonance strengths, we make a canonical transformation of the Hamiltonian Eq. (2) with the generating function of the form:

$$
\begin{gathered}
G\left(k_{x}, K_{z}, \phi_{x}, \phi_{z}, s\right)=k_{x} \phi_{x}+k_{z} \phi_{z}^{-}+ \\
\sum_{k} \frac{g_{k}\left(k_{x}, k_{z} s\right)}{\sin \pi\left(n_{x_{k}} \nu_{x}+n_{z_{k}} \nu_{z}\right)} \cos \left(n_{x_{k}} \phi_{x}+n_{z_{k}} \phi_{z}+\theta_{k}\right)
\end{gathered}
$$


Where $g_{k}(K x, K z, s)$ are the generating function 'resonance strengths whose magnitude shows to what extent $\mathrm{Jx}$ and $\mathrm{Jz}$ deviate from the invariants of the motion. The $n_{x_{k}}$ and $n_{z_{k}}$ are integers defining a given resonance and $\theta_{k}$ are the phase.

The new Hamiltonian can be found from the generating function as ;

$$
H_{2}=H_{1}\left(J_{X}, J_{z}, \Phi_{X}, \Phi_{Z}, s\right)+\frac{\partial}{\partial s} G\left(K_{X}, K_{z}, \Phi_{X}, \Phi_{z}, s\right)
$$

with

$$
\begin{aligned}
J_{X} & =\frac{\partial}{\partial \phi_{X}} G\left(K_{X}, K_{z}, \phi_{X}, \phi_{Z}, s\right) \\
& =E_{x} / 2 \pi \\
J_{z} & =\frac{\partial}{\partial \phi_{z}} G\left(K_{X}, K_{Z}, \phi_{X}, \phi_{Z}, s\right) \\
& =E_{z} / 2 \pi
\end{aligned}
$$

and the new angle variables;

$$
\begin{aligned}
& \Psi_{x}=\frac{\partial}{\partial K_{X}} G\left(K_{X}, K_{Z}, \phi_{X}, \phi_{Z}, s\right) \\
& \Psi_{z}=\frac{\partial}{\partial K_{z}} G\left(K_{X}, K_{Z}, \phi_{X}, \phi_{Z}, s\right)
\end{aligned}
$$

With $\mathrm{Kx}, \mathrm{Kz}, \psi_{\mathrm{X}}$ and $\psi_{\mathrm{z}}$ as the new action and angle variables respectively

$$
\begin{aligned}
\psi_{x}= & \phi_{x}+\sum_{k}\left[\frac { \partial } { \partial k _ { x } } g _ { k } ( k _ { x } , k _ { z } , s ) \operatorname { c o s } \left(n_{x_{k}} \phi_{x}+n_{z_{k}} \phi_{z}\right.\right. \\
& \left.+\theta_{k}\right)-g_{k}\left(k_{x}, k_{z}, s\right) \frac{\partial}{\partial k_{x}} \theta_{k}\left(k_{x}, k_{z}, s\right) \sin \left(n_{x_{k}} \phi_{x}+\right. \\
& \left.\left.+n_{z_{k}} \phi z+\theta_{k}\right)\right] \frac{1}{\sin \pi\left(n_{x_{k}}{ }^{v}+n_{z_{k}} \nu_{z}\right)}
\end{aligned}
$$

and 


$$
\begin{aligned}
& \psi_{z}=\phi_{z}+\sum_{k} \frac{\partial}{\partial k_{z}} g_{k}\left(k_{x}, k_{z}, s\right) \cos \left(\pi_{x_{k}} \phi_{x}+n_{z_{k}} \phi_{z}\right. \\
& \left.+\theta_{k}\right)-g_{k}\left(k_{x}, k_{z}, s\right) \frac{\partial}{\partial k_{z}} \theta_{k}\left(k_{x}, k_{z}, s\right) \sin \left(n_{x_{k}} \phi_{x}\right.
\end{aligned}
$$

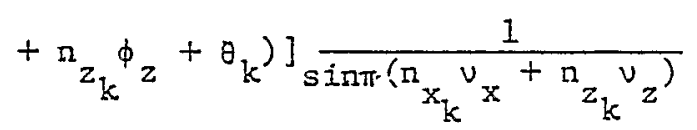

Thus the perturbation on the tune due to the nonlinear elements (e.g. sextupoles and octupoles) can be found as

$$
\begin{gathered}
\frac{d}{d s} \psi_{X}(s)=\frac{\partial H}{\partial K_{X}} \\
\frac{d}{d s} \psi_{x}=\frac{1}{B_{x}(s)}+2 a(s) K_{X}+b(s) K_{z}
\end{gathered}
$$

and

$$
v_{x} \equiv \frac{1}{2 \pi} \cdot \int_{0}^{C}\left[\frac{d}{d s} \psi_{x}(s)\right] d s
$$

or

$$
v_{x}=v_{x}^{0}+2 \alpha_{x x} k_{x}^{*}+2 \alpha_{x z} K_{z}
$$

Similarly,

where

$$
\begin{aligned}
& v_{z}=v_{z}^{j}+2 \alpha_{z z} k_{z}+2 \alpha_{x z} k_{x} \\
& \alpha_{x x}=1 / \pi \int_{0}^{C} a(t) d t, \alpha_{x z}=\frac{1}{2 \pi} \int_{0}^{C} b(t) d t
\end{aligned}
$$

with

$$
\alpha_{z z}=1 / \pi \int_{0}^{C} c(t) d t
$$

Where the coefficients $a(s), b(s)$ and $c(s)$ are given in Reference 1 , and the machine tunes $v_{x}$ and $v_{z}$ depends on the beam enittance. The $v_{x}^{0}$ and $\nu_{z}^{0}$ are the unperturbed tunes and $2 \mathrm{Kx}, 2 \mathrm{Kz}$ are average beam emittances divided by $\pi,\left\langle E_{X}\right.$ and $\left\langle E_{Z}\right\rangle$ " and 


$$
\begin{aligned}
& v_{x}^{0}=\frac{1}{2 \pi} \int_{0}^{C} \frac{d t}{\beta_{x}(t)} \\
& v_{z}^{0}=\frac{1}{2 \pi} \int_{0}^{C} \frac{d t}{\beta_{z}(t)}
\end{aligned}
$$

Thus we find the emittance growth to be

$$
\begin{aligned}
& E_{x} \doteq 2 \pi\left[k_{x}+\sum_{x} n_{x_{k}}\left|\frac{g_{k}\left(k_{x}, k_{z}, s\right)}{\sin \pi\left(n_{x_{k}} \nu_{x}+n_{\left.z_{k} v_{z}\right)}\right.}\right|\right] \\
& E_{z} \leqq 2 \pi\left[k_{z}+\sum_{k} n_{z_{k}}\left|\frac{g_{k}\left(k_{x}, k_{z}, s\right)}{\sin \pi\left(n_{x_{k}} \nu_{x}+n_{\left.z_{k} \nu_{z}\right)}\right.}\right|\right]
\end{aligned}
$$

These estimate the upper Iimit that emittance grow to as Iong as the tunes are far from any resonances

Further, we can deduce the contribution of a single resonance to the emittance growth:

$$
\begin{aligned}
-E_{x} & =2 \pi\left[K_{x}+n_{x} \frac{a\left(k_{x}, K_{z}\right)}{\delta} \cos \left(n_{x} \phi_{x}+n_{z} \phi_{z}\right.\right. \\
& \left.\left.-\frac{2 \pi}{c} p s+\theta\right)\right] \\
E_{z} & =2 \pi\left[k_{z}+n_{z} \frac{a\left(k_{x}, k_{z}\right)}{\delta} \cos \left(n_{x} \phi_{x}+n_{z} \phi_{z}\right.\right. \\
& \left.\left.-\frac{2 \pi}{C} p s+\theta\right)\right]
\end{aligned}
$$

with $n_{x}>0$ when $n_{z}<0$ for difference resonances. The emittance oscillates about its average value (with oscillation amplitude proportional to $g(J x, J z)=a(J x, J z) / \delta)$, where $\delta$ is the bandwidth (e.g. $\delta=0$ near resonance) defined as

$$
\delta \equiv n_{x} v_{x}+n_{z} v_{z}-p
$$

which determines how far the tunes $v_{x}$ and $v_{z}$ are from the resonance (defined by integers $n_{x^{\prime}} n_{z}$ and $\mathrm{p}$ ). 
SMEAR

To.find the "smear" (that 1s, the measure of the extent to which the emittance deviates from an invarlant of the motion) we consider the variation of the emittance with respect to the time variable of the Hamlitonian s. The coefficients of equations $(.14 \div 17 \%)$ which are periodic functions of $s, \phi_{x}$ and $\phi_{z}$; can be expressed as functions of $s$ times the sine and cosine of $\left(n_{X} \phi_{X}+n_{Z} \phi_{Z}\right)$. Then keeping $\phi_{X}$ and $\phi_{Z}$ fixed, the emittance is periodic in $s$ :

$$
\begin{aligned}
& E_{X}\left(\phi_{X}, \phi_{Z}, K_{X}, K_{Z}, s\right)=E_{X}\left(\phi_{X}, \phi_{Z}, K_{X}, K_{Z}, s+C\right), \\
& E_{Z}\left(\phi_{X}, \phi_{Z}, K_{X}, K_{Z}, s\right)=E_{Z}\left(\phi_{X}, \phi_{Z}, K_{X}, K_{Z}, s+C\right)
\end{aligned}
$$

Where $C$ is the circumference of the accelerator.

Note that, as we increase $s$ by $c$ then to the lowest order $\phi x$ increases by $2 \pi v_{X}$ and $\phi_{Z}$ increases by $2 \pi v_{Z}$. Thus, overall $E_{X}$ and $E_{z}$ does not remain periodic in $s$ if we include the $\phi_{x}$ and $\phi_{z}$ dependence of $s$. From the phase plots of $E_{X}$ (or $E_{X}^{1 / 2}$ ). versus $\dot{\phi}_{X}$ Fig. 1 we note that, if we had no non-linear elements all the points would fall on the line $E_{X}=E_{X}$ (Ave $E_{X}$ ).

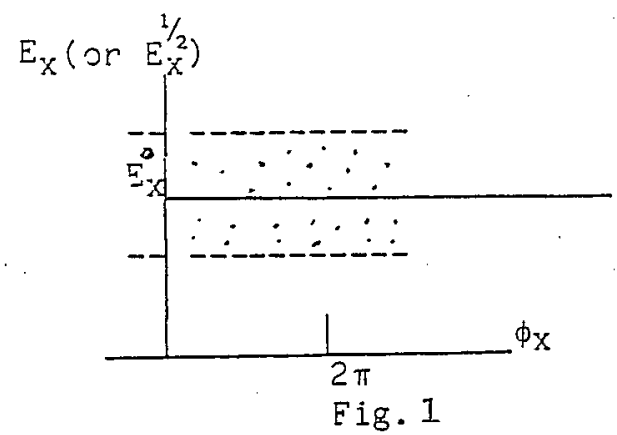


Since the nonlinear elements cause the deviation from this line, we can find the measure of this deviation from the "standard deviation" $D\left(E_{X}\right)$ which is related to the emittance as $D\left(E_{X}\right)=\delta E_{X}$, where smear is defined from the standard deviation of $E_{x}^{1 / 2}$

$$
D\left(E_{X}^{1 / 2}\right)=\text { smear }=\left[\frac{\sigma_{X}^{2}+\sigma_{Z}^{2}}{\left\langle E_{X}^{1 / 2}\right\rangle+\left\langle E_{Z}^{1 / 2}\right\rangle^{2}}\right]^{1 / 2}
$$

where $\sigma_{X}=\left\langle E_{X}\right\rangle-\left\langle E_{X}^{1 / 2}\right\rangle{ }^{2}$ and $\sigma_{z}=\left\langle E_{z}\right\rangle-\left\langle E_{z}^{1 / 2}\right\rangle^{2}$ or

$$
\text { smear }=\left[\frac{\left\langle E_{X}\right\rangle+\left\langle E_{7}\right\rangle}{\left\langle E_{X}^{1 / 2}\right\rangle^{2}+\left\langle E_{Z}^{1 / 2}\right\rangle 2}-1\right]^{1 / 2}
$$

and as a simpler alternative, the smear can be defined as:

$$
\begin{aligned}
& \text { Smear }_{x} \cong \frac{1}{\sqrt{3}} \frac{E_{x}(\max )-E_{x}(\min )}{\left\langle E_{x}\right\rangle}=\frac{1}{\sqrt{3}}\left|n_{x} g\left(J_{x}, J_{z}\right)\right| \\
& \text { Smear }_{z} \cong \frac{1}{\sqrt{3}} \frac{E_{z}(\max )-E_{z}(\min )}{\left\langle E_{z}\right\rangle}=\frac{1}{\sqrt{3}}\left|n_{z} g\left(J_{x}, J_{z}\right)\right|
\end{aligned}
$$

Which are useful for obtaining the resonance coupling strength $g(J x, J z)$, (e.g. from the tracking results).

\section{LINEAR APERTURE}

We obtain the linear aperture a from $a=\sqrt{\beta_{\max } E_{0} / \pi}$, where $\beta_{\max }$ is the maximum betatron amplitude and $E_{0}$ is the initial beam emittance which gives a smear of 0.1 . 
Finally in our analysis of the beam behavior versus chromaticity ( $\xi$ ) we consider

$$
\xi_{x(\text { or } z)}=\frac{1}{4 \pi} \int_{0}^{C}\left(-K(s)_{\text {or } z)} \pm S(s) D(s)\right) B_{x(\text { or } z)} d s
$$

with $K(s)$ the quadrupole focusing strength, $S(s)$ is the sextupole strength (including Focusing, Defocusing and Eddy current in one case and sextupoles due to saturation in the second case respectively). Where $D(s)$ is the horizontal dispersion and $B(s)$ is the betatron function.

Thus, we first calculate the sextupole strengths inorder to obtain the desired chromaticity then using second order perturbation theory we study the effect of the sextupoles (e.g. due to eddy current, chromatic correction and saturation) on the bean. In addition we compare the ordinary perturbation theory with the superconvergent perturbation theory, illustrating the amplitude dependence of the tune cue to nonlinear elements in an accelerator. 
AGS-BOOSTER

Due to the interest and request for more information on the Booster (during my April 187 talk) I first give an overview of the AGS Booster (the Parameter List) and a comparison of our analytic results (for the Booster) with results obtained from program HARMON and tracking programs PATRICIA and ORBIT.

The AGS-Booster is designed to be an intermediate synchrotron injector for the AGS with the capability of accelerating protons from 200 MeV to 1.5 $\mathrm{GeV}$ (with the possibility of an upgrde to $2.5 \mathrm{GeV}$ ), and capable of accelerating heavy ions to a magnetic rigidity equal to 17.52 Tesla meters at a $1 \mathrm{~Hz}$ repetition rate. The Booster has six identical superperiods and circumference of $201.78 \mathrm{~m}$; with an operating point at $v_{x}=4.82$ and $v_{z}=4.83$. The goal for the Booster is to increase the AGS proton and polorized proton intensities (by factors of 4 and 20 (to 30) respectively) in addition to enabling the acceleration of all species of heavy ions at the AGS. To increase the number of particles per bunch in the AGS, we need a high intensity beam in the Booster which may produce a large space charge tune shift in the Booster at injection. That space charge tune shift can use crossing of the fourth order structure resonances $4 v_{X}=18,2 v_{X}+2 v_{z}=18$ and $4 v_{z}=18 ;$ (and possibly the $2 v_{x}-2 v_{z}=0$ resonance), thereby destabalizing the beam. Depending on the amount of the tune shift the third and sixth order resonances may have to be examined (at operating tunes of approximately $v_{x}=4.01$ and $v_{z}=4.11$ ). 
QUICK REFERENCE

AGS BOOSTER PARAMETER LIST

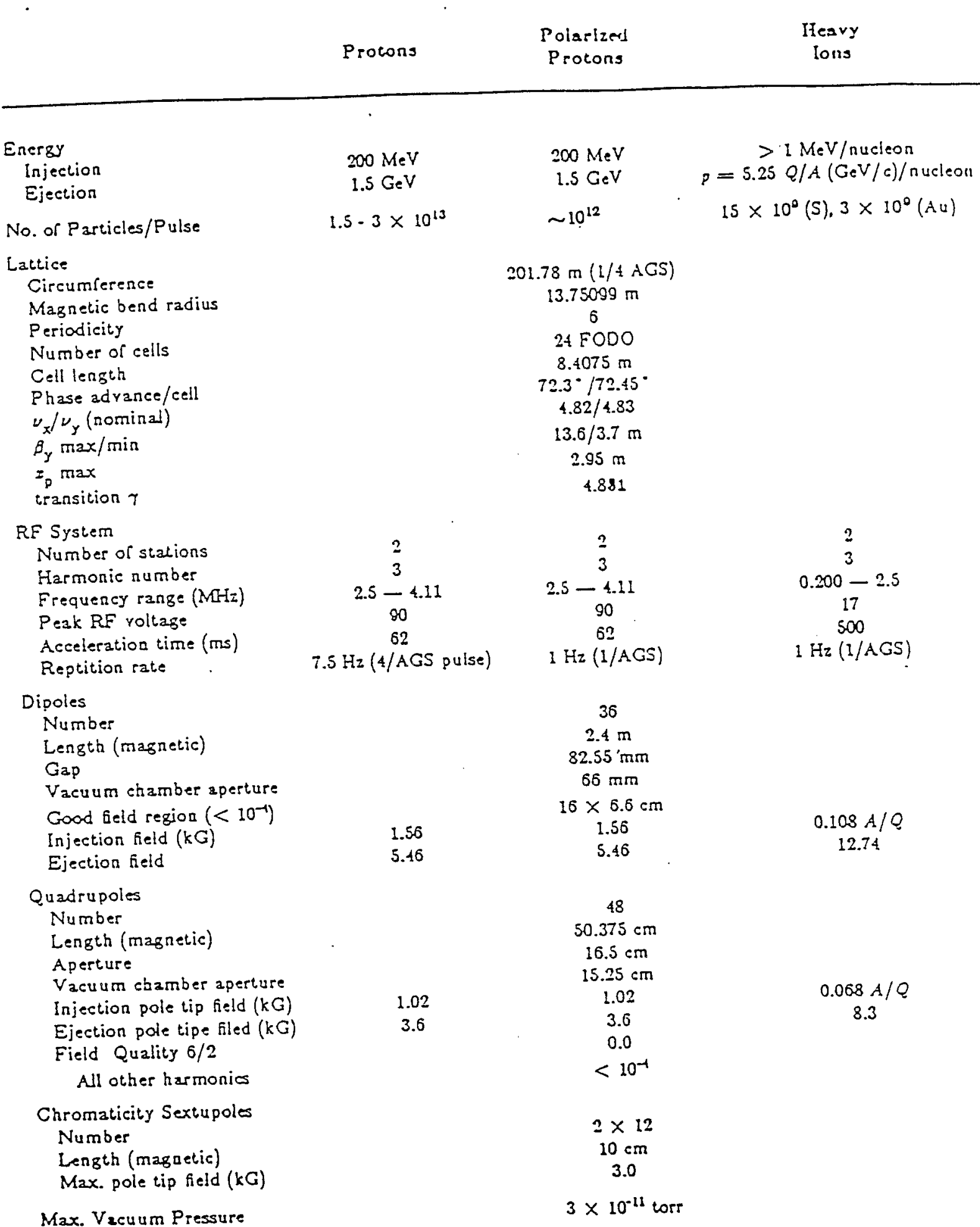

Max. Vicuum Pressure

Reference: Z. Parsa, Booster Parameter List, BNL-393I1, 1987; and Design Manual. 
T.tDIE I. Isotopes, Charge Stutes, and Ionic Minsses.

\begin{tabular}{|c|c|c|c|c|c|}
\hline & $Q$ & $Z$ & $A$ & $\begin{array}{c}\text { Ionic } \\
\text { Resi } \backslash \text { lass } \\
\text { (1) }\end{array}$ & $\begin{array}{c}\text { Icnic } \\
\text { Resi hlass } \\
\text { E=ero: } \\
\text { (GeV/zucieca) }\end{array}$ \\
\hline פִ & $\div 1$ & 1 & 1 & 1.007 .9 & 0.92329 \\
\hline$\dot{d}$ & $\div 1$ & 1 & 2 & 2.01335 & 0.93681 \\
\hline$C$ & $\div 6$ & 6 & 12 & 11.99671 & 0.93125 \\
\hline S & $\div 1=$ & 16 & 32 & $31.96 \pm 39$ & 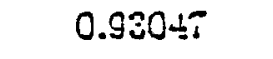 \\
\hline $\mathrm{Cu}_{\mathrm{I}}$ & $\div 21$ & 20 & 63 & 62.91808 & 0.93029 \\
\hline$I$ & $\div 20$ & 53 & Iก: & 125.3885T & 0.33065 \\
\hline$\therefore$ & $\div 33$ & $T 9$ & 197 & $196.9 \div 3 \div 6$ & $0.931: 5$ \\
\hline
\end{tabular}

TABIE 2. Injection Energies and Fields

\begin{tabular}{|c|c|c|c|c|c|c|}
\hline & \multirow{2}{*}{$y / c$} & \multirow{2}{*}{$\begin{array}{c}f \\
\text { (즈드) }\end{array}$} & \multirow{2}{*}{$\begin{array}{c}p \\
(\mathrm{GeV} / \mathrm{c})\end{array}$} & \multicolumn{2}{|r|}{$E_{i n j}$} & \multirow{2}{*}{$\begin{array}{l}B_{i n j} \\
(k C)\end{array}$} \\
\hline & & & & $(\mathrm{M}[\mathrm{eV})$ & (MLeV/nucieos) & \\
\hline$p$ & 0.3062 & 2.5235 & $0.54 \div$ & 200.0 & 200.000 & 1.503 \\
\hline ¿ & 0.1765 & 0.7878 & 0.3368 & 30.0 & $15.0 C 0$ & $0.9 \mathrm{IB}$ \\
\hline C & 0.1252 & 0.50 .3 & 1.4211 & 90.0 & 7.500 & 0.575 \\
\hline $\mathrm{S}$ & 0.1000 & 0.4457 & 2.9925 & 150.0 & 4.688 & 0.519 \\
\hline $\mathrm{Cu}_{-}$ & 0.0782 & $0.3 \div 85$ & 4.5969 & 180.0 & 2.857 & 0.531 \\
\hline$I$ & 0.0595 & 0.2553 & $7.0 \leq 89$ & 210.0 & $1.55 \div$ & 0.550 \\
\hline \pm 11 & $0.0 \div 13$ & 0.2131 & 8.7805 & 210.0 & 1.066 & 0.54 .5 \\
\hline
\end{tabular}

IABIE 3. Ejection Energies anc Fields $-B_{\max }=12.7 \div \mathrm{kG}$

\begin{tabular}{|c|c|c|c|c|c|c|}
\hline & \multirow[t]{2}{*}{$\because / c$} & \multirow{2}{*}{$\begin{array}{c}f \\
M E=-1\end{array}$} & \multirow{2}{*}{$\begin{array}{c}P \\
(G+V i c)\end{array}$} & \multicolumn{2}{|r|}{$E_{j ;:=}$} & \multirow{2}{*}{$\begin{array}{l}E_{i j:=} \\
\because: G:\end{array}$} \\
\hline & & & & $(G=V)$ & $(G=\nabla / \Omega u c i s c z i$ & \\
\hline 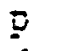 & 0.23030 & $4.11 \div$ & $2.85 i$ & $1 .=00$ & $1.50 C O$ & 5.53 \\
\hline$\dot{d}$ & 0.9699 & 3.5T & 3.308 & 1.925 & $0.963 \overline{3}$ & $8.0 \Omega=$ \\
\hline C & 0.9714 & $3.88 \div$ & $19.8 \div \pi$ & 11.502 & 0.96068 & $8.02 \div$ \\
\hline$S$ & 0.9 .15 & $3.9 \$ 5$ & 52.225 & 30.952 & $0.96: 2$ & 0.1 .0 \\
\hline $\mathrm{Cu}$ & $0.953 \div$ & $3.80 \div$ & 9.5 .332 & $53 . \$ 10$ & $0.85 \pm I$ & 11.081 \\
\hline I & 0.7000 & 3.322 & $152.3 \div 3$ & $7 \pm .6 \Omega 3$ & 0.3880 & $12.7 \div 3$ \\
\hline$\therefore u$ & 0.6863 & $3.06 i$ & 173.25 .8 & 68.0.01 & 0.3500 & $12.0 \div 0$ \\
\hline
\end{tabular}

Reference: Z. Parsa, Booster Parameter List, BNL-39311, 1987 ; and Design Manual. 
IAgre 1. Isoroges, Charge Siries, and Ionic MInses.

\begin{tabular}{|c|c|c|c|c|c|}
\hline & $Q$ & $Z$ & $A$ & $\begin{array}{c}\text { Iosic } \\
\text { Rest ylass } \\
\text { (u) }\end{array}$ & $\begin{array}{c}\text { Icaic } \\
\text { Resi Mlass } \\
\text { Eneray } \\
\text { (GeV/nucieon) }\end{array}$ \\
\hline Dַ & $\div 1$ & 1 & 1 & 1.00728 & 0.93828 \\
\hline d & $\div 1$ & 1 & $\underline{?}$ & 2.01355 & $0.93781^{\circ}$ \\
\hline C & $\div 6$ & 6 & 12 & $11.996 T 1$ & 0.93125 \\
\hline$S$ & $\div 14$ & 16 & 32 & $31.96 \div 39$ & $0.9304 T$ \\
\hline $\mathrm{Cu}$ & $\div 21$ & 23 & 63 & 6291808 & 0.93029 \\
\hline$I$ & $\div 20$ & 33 & $I I$ & 126.88857 & 0.93068 \\
\hline$\therefore 1$ & $\div 33$ & 79 & $I \cong T$ & 196.94846 & 0.03126 \\
\hline
\end{tabular}

TABIE 2. Injection Energies and Fields

\begin{tabular}{|c|c|c|c|c|c|c|}
\hline & \multirow[t]{2}{*}{$v / c$} & \multirow{2}{*}{$\begin{array}{c}f \\
(M I E z)\end{array}$} & \multirow{2}{*}{$\begin{array}{c}P \\
(\mathrm{GeV} / \mathrm{c})\end{array}$} & \multicolumn{2}{|r|}{$E_{i n j}$} & \multirow{2}{*}{$\begin{array}{l}B_{i n j} \\
(k G) \\
\end{array}$} \\
\hline & & & & $(\mathrm{M}(\mathrm{eV})$ & (MleV/nucieso) & \\
\hline$p$ & 0.5662 & 2.5235 & 0.6444 & 200.0 & 200.000 & 1563 \\
\hline$a$ & 0.1767 & 0.7873 & 0.3368 & 30.0 & $15 . C C O$ & 0.817 \\
\hline C & 0.1262 & 0.5623 & 1.4211 & 90.0 & 7.500 & 0.575 \\
\hline$s$ & 0.1000 & 0.4457 & 2.9925 & 150.0 & 4.688 & 0.519 \\
\hline $\mathrm{Cu}$ & 0.0782 & 0.3485 & $4.5 q 789$ & 180.0 & 2857 & 0.531 \\
\hline I & 0.0595 & 0.2653 & 7.0489 & $2=0.0$ & 1.654 & 0550 \\
\hline$\therefore 1$ & 0.0478 & 0.2131 & 8.7805 & 220.0 & $1.06 t^{\circ}$ & 0.645 \\
\hline
\end{tabular}

TABIE 3. Ejection Energies and Fieids $-B_{\max }=12.7 \pm \mathrm{kG}$

\begin{tabular}{|c|c|c|c|c|c|c|}
\hline & \multirow[t]{2}{*}{$v / c$} & \multirow{2}{*}{$\begin{array}{c}f \\
M E=2\end{array}$} & \multirow{2}{*}{$\begin{array}{c}p \\
(G=\bar{v} i c) \\
\end{array}$} & \multicolumn{2}{|r|}{$E_{j ;:=}$} & $E_{\text {,i:s }}$ \\
\hline & & & & $(\mathrm{C}=\bar{v})$ & $E \pm \pi /=$ & 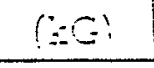 \\
\hline $\begin{array}{l}\bar{g} \\
\dot{C} \\
C \\
S \\
\mathrm{Cu} \\
I \\
\mathrm{~A} u\end{array}$ & $\begin{array}{l}0.8699 \\
0.8714 \\
0.8716 \\
0.8534 \\
0.7000 \\
0.6863 \\
\end{array}$ & $\begin{array}{l}4.114 \\
3.877 \\
3.884 \\
3.885 \\
3.804 \\
3.582 \\
3.061 \\
\end{array}$ & $\begin{array}{r}2.251 \\
3.308 \\
19.841 \\
52.926 \\
95.932 \\
153345 \\
173.359 \\
\end{array}$ & $\begin{array}{r}1.500 \\
1.927 \\
11.602 \\
30.952 \\
58.810 \\
14.623 \\
68,050 \\
\end{array}$ & $\begin{array}{l}0.9696 \\
0.9672 \\
0.8541 \\
0.58500 \\
0.3500\end{array}$ & $\begin{array}{l}5.459 \\
8.024 \\
8.024 \\
9.170 \\
1.081 \\
12743 \\
12.743\end{array}$ \\
\hline
\end{tabular}

Refezence: Z. Parsa, Booster Parameter List, Birl-3931I, 1987 ; and Design Manual. 

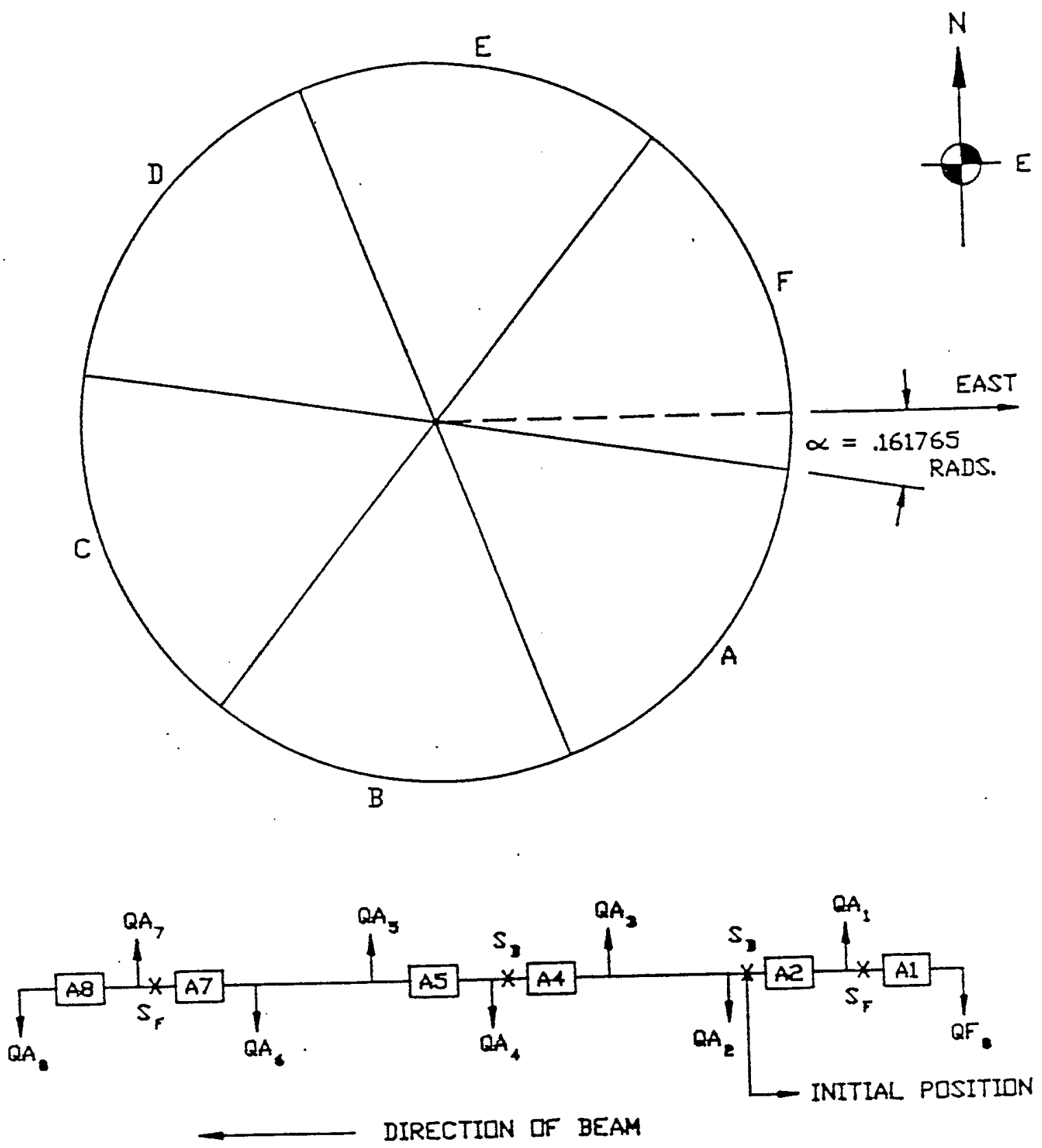

$\{$ = FICUSING QUADRUPDLE

$\downarrow=$ DEFDCUSING QUADRUPDLE $\square=$ BENDING MAGNET (DIPQLE)

$X=$ SEXTUPQLE

FIG. 2 a) Schematic Diagram of the Booster and

b) Components of the Superperiod including two familles of chromaticity correcting sextupoles (chosen), located at 1.7 (SF), 2,4 (SD) per
superperlod (each of $10 \mathrm{~cm}$ length with aperture of $15.52 \mathrm{~cm})$. 


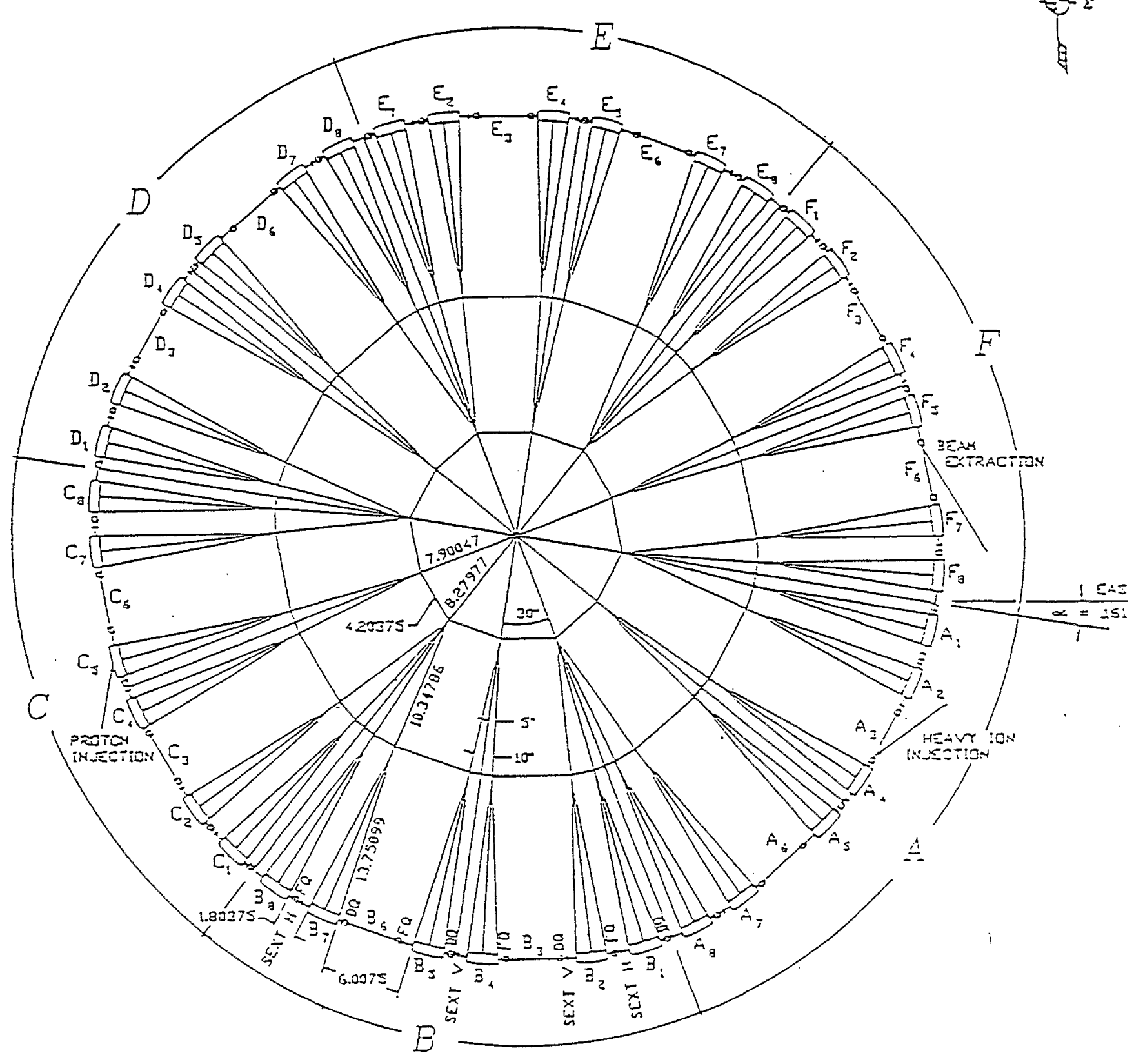

Figure 3. The layout of the Booster. 
IASLE 4 R: S:S:-N:

\begin{tabular}{|c|c|c|c|c|}
\hline & $?$ & pi & $s^{-: i}$ & $\therefore-\approx$ \\
\hline \multicolumn{5}{|l|}{ R-Ampiizude } \\
\hline 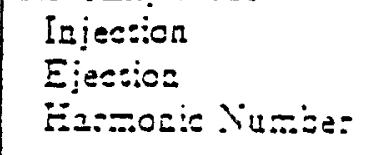 & $\begin{array}{c}90: \because \\
90: \because \\
3\end{array}$ & $\begin{array}{c}-.33: y \\
40: \because \\
3\end{array}$ & $\begin{array}{c}0.5 i: \because \% \\
17: \because 4 \\
3\end{array}$ & $\begin{array}{l}1.5:- \\
17:- \\
3\end{array}$ \\
\hline 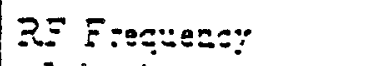 & & & & \\
\hline $\begin{array}{c}\text { injes:ic= } \\
\text { Eit: }\end{array}$ & 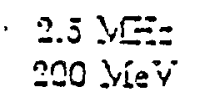 & $\begin{array}{l}2.5 \text { VE: }= \\
200 \text { Vis }\end{array}$ & 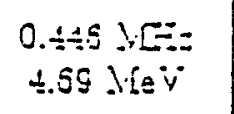 & $\begin{array}{l}0.925 \text {. } \\
1.07=0=\end{array}$ \\
\hline Ejection & $5.11 . \mathrm{VEF}=$ & $\pm .11 .2 E=$ & $4.13 \times E=$ & $3.06 \mathrm{~V} \times[\mathrm{Z}=$ \\
\hline PLasa Souce ․:-an!. & $\geq 1.0 \mathrm{er}-\bar{r}$ & $0 . \hat{j} e \ddot{y}-z$ & 0.060 e $\ddot{v}=s$ & 0.050 evis \\
\hline $\begin{array}{l}\text { Incensicy ipaz=istes } \\
\text { (pez buaci) }\end{array}$ & $10^{: 2}$ & $\operatorname{sol} 1 \times 10^{i i}$ & $3 \times 10^{3}$ & $5 \times 10^{3}$ \\
\hline 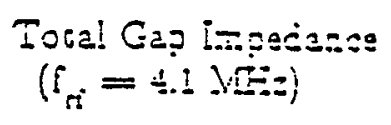 & $<2 \div 1$. & : 10 1 & io Iimi= & So $1:=i=$ \\
\hline Acos!erz:icn Fina & $02 \pi s$ & $\leq 0.5 \leq$ & $\leq 0.3 \mathrm{~s}$ & $\leq 0.5 \leq$ \\
\hline $\begin{array}{l}\text { Mlaxinun Power } \\
\text { Deiivelec io Besa. }\end{array}$ & $I=5: \because V$ & $<2 \mathrm{kip}$ & $<1.0 \mathrm{kir}$ & $<2 \sin$ \\
\hline$\underset{\dot{\Xi}_{\text {inj }}}{M \text { Maximur } \dot{\Xi}}$ & $\begin{array}{l}0.5 \mathrm{I} / \mathrm{s} \\
1.5 \mathrm{I} / \mathrm{s}\end{array}$ & $\begin{array}{c}4.5 \mathrm{I} / \mathrm{S} \\
?\end{array}$ & $<0.15 \mathrm{I} / \mathrm{s}$ & $<0.15 \pm / 5$ \\
\hline
\end{tabular}

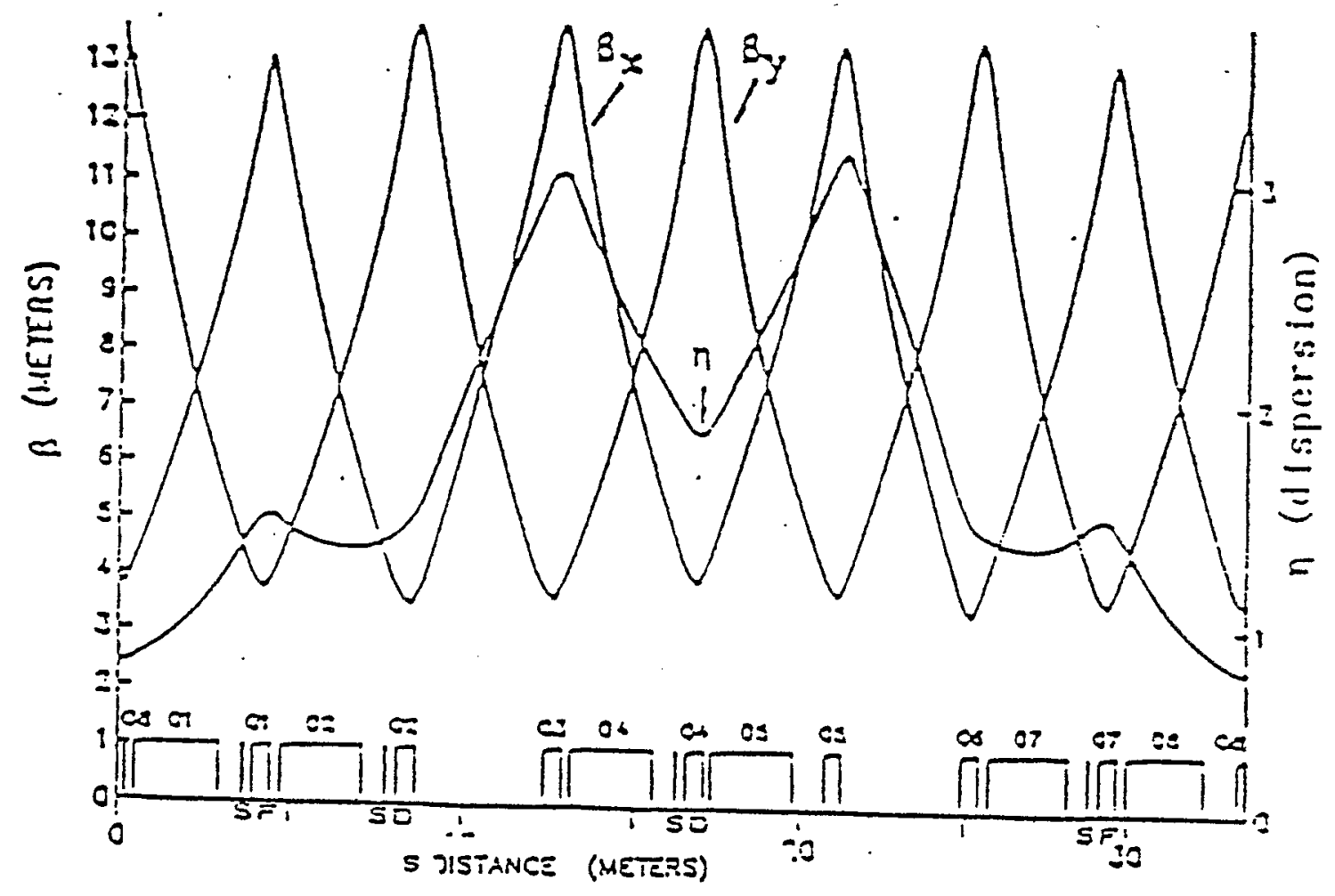

Fig.4, shows the betatron functions and the amplitude dependence of tunes for the ACS sosster. 
We have studled the effect of the systemat 1c resonances 1.7 the Booster; and in Table II and IIf, we present some of our results (obtained using program HARMON a.d NONLIN), for the third and fourth order resonances. These and higher order resonances are clscussed in Reference $[2]$, since HaAMON is $11 \mathrm{~m} 1 \mathrm{ted}$ to the calculation of fourth order resonances.

-I. shows the perturbation to tune $\left(Q_{x}^{\prime}, Q_{z}^{\prime}\right)$ at the corresoonding operating (linear) tunes $\left(Q_{x}, Q_{z}\right)$ at which the resonances were investigated.

TABLE I. : TUne Shift

\begin{tabular}{|c|c|c|c|}
\hline \multicolumn{2}{|c|}{ Operating Tunes } & \multicolumn{2}{|c|}{ Perturbed Tunes } \\
\hline$Q_{x}$ & $Q_{z}$ & $\Phi_{x}$ & $Q_{z}^{\prime}$ \\
\hline 4.82 & 4.83 & 4.820476 & 4.834616 \\
\hline 4.501 & 4.511 & 4.500944 & 4.514804 \\
\hline 4.001 & 4.011 & 3.982678 & 4.000854 \\
\hline
\end{tabular}

Tables I - III shows that the results obtained from HAMMON and NONLIN agrees quite well with the largest difference in the fourth order resonances (due to the 2nd order sextupole effects). 
TABLE II AGS-Booster Lattice [NONLIN]

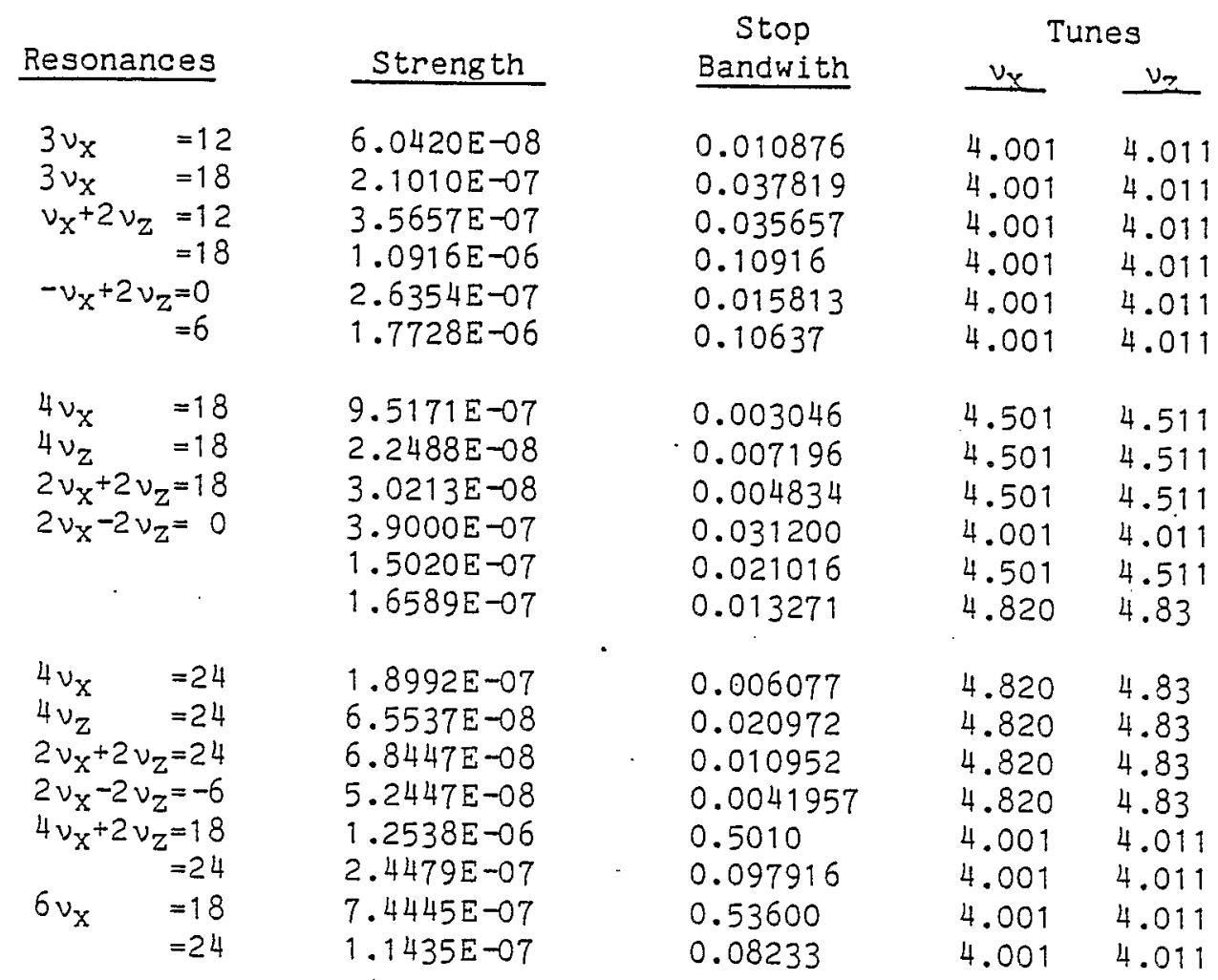


TABLE III AGS-Booster Lattice [HARMON]

\begin{tabular}{|c|c|c|c|c|}
\hline \multirow{2}{*}{ Resonances } & \multirow{2}{*}{ Strength } & \multirow{2}{*}{$\begin{array}{c}\text { Stop } \\
\text { Bandwith }\end{array}$} & \multicolumn{2}{|c|}{ Tunes } \\
\hline & & & $v_{x}$ & $v_{2}$ \\
\hline $3 v_{x}$ & $6.04187 \varepsilon-08$ & 0.010876 & 4.001 & 4.011 \\
\hline $3 v_{x}^{n}$ & $2.10103 E-07$ & 0.037819 & 4.001 & 4.011 \\
\hline$v_{x}+2 v_{z}=12$ & $3.56559 E-07$ & 0.035657 & 4.001 & 4.011 \\
\hline$=18$ & $1.09163 \mathrm{E}-06$ & 0.10916 & 4.001 & 4.011 \\
\hline$-v_{x}+2 v_{z}=0$ & $1.633876 \mathrm{E}-07$ & $* * * * * * *$ & 4.001 & 4.011 \\
\hline$\therefore,=6$ & $1.77282 \mathrm{E}-06$ & $* * * * * * *$ & 4.001 & 4.011 \\
\hline $4 v_{x}$ & $7.64062 E-09$ & 0.001223 & 4.501 & 4.511 \\
\hline $4 v_{z}^{x}$ & $1.08154 \mathrm{E}-08$ & 0.001731 & 4.501 & 4.511 \\
\hline $2 v_{x}+2 v_{z}=18$ & $3.13890 E-08$ & 0.002511 & 4.501 & 4.511 \\
\hline $2 v_{x}-2 v_{z}=0$ & $1.9042 E-07$ & $* * * * * * *$ & 4.001 & 4.011 \\
\hline & $1.10073 E-07$ & $* * * * * * *$ & 4.501 & 4.511 \\
\hline & $1.2424 E-07$ & $* * * * * * *$ & 4.820 & 4.830 \\
\hline $4 v_{x}$ & $6.8891 E-09$ & 0.0011023 & 4.820 & 4.830 \\
\hline $4 v_{z}$ & $1.84457 E-08$ & 0.00295135 & 4.820 & 4.830 \\
\hline $2 v_{x}+2 v_{z}=24$ & $7.002513 E-08$ & 0.005602 & 4.820 & 4.830 \\
\hline $2 v_{x}-2 v_{z}=-6$ & 13.446 & $* * * * * * *$ & 4.820 & 4.830 \\
\hline
\end{tabular}




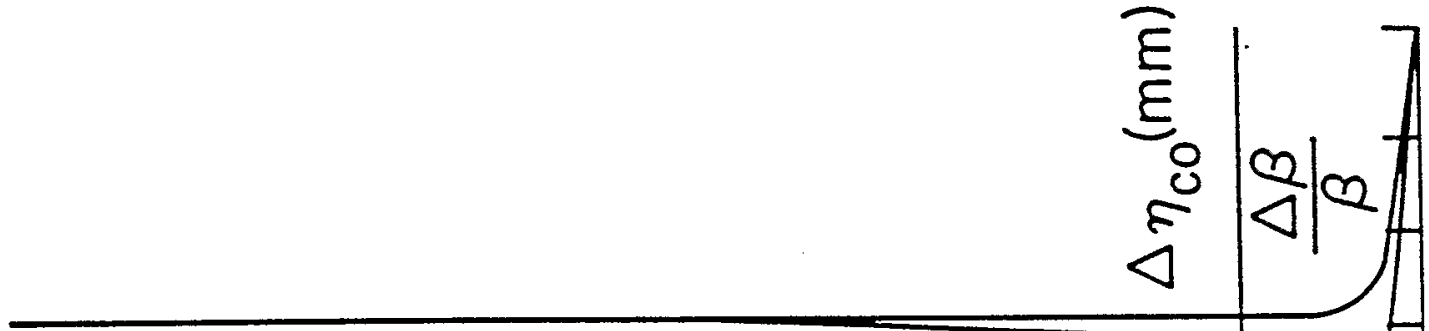

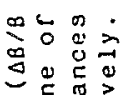

들

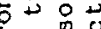

它

告

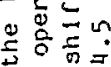

苛苍亭

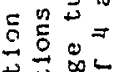

त)

든

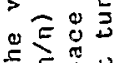

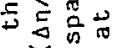

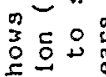

के

的家

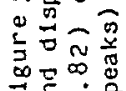

เทำ
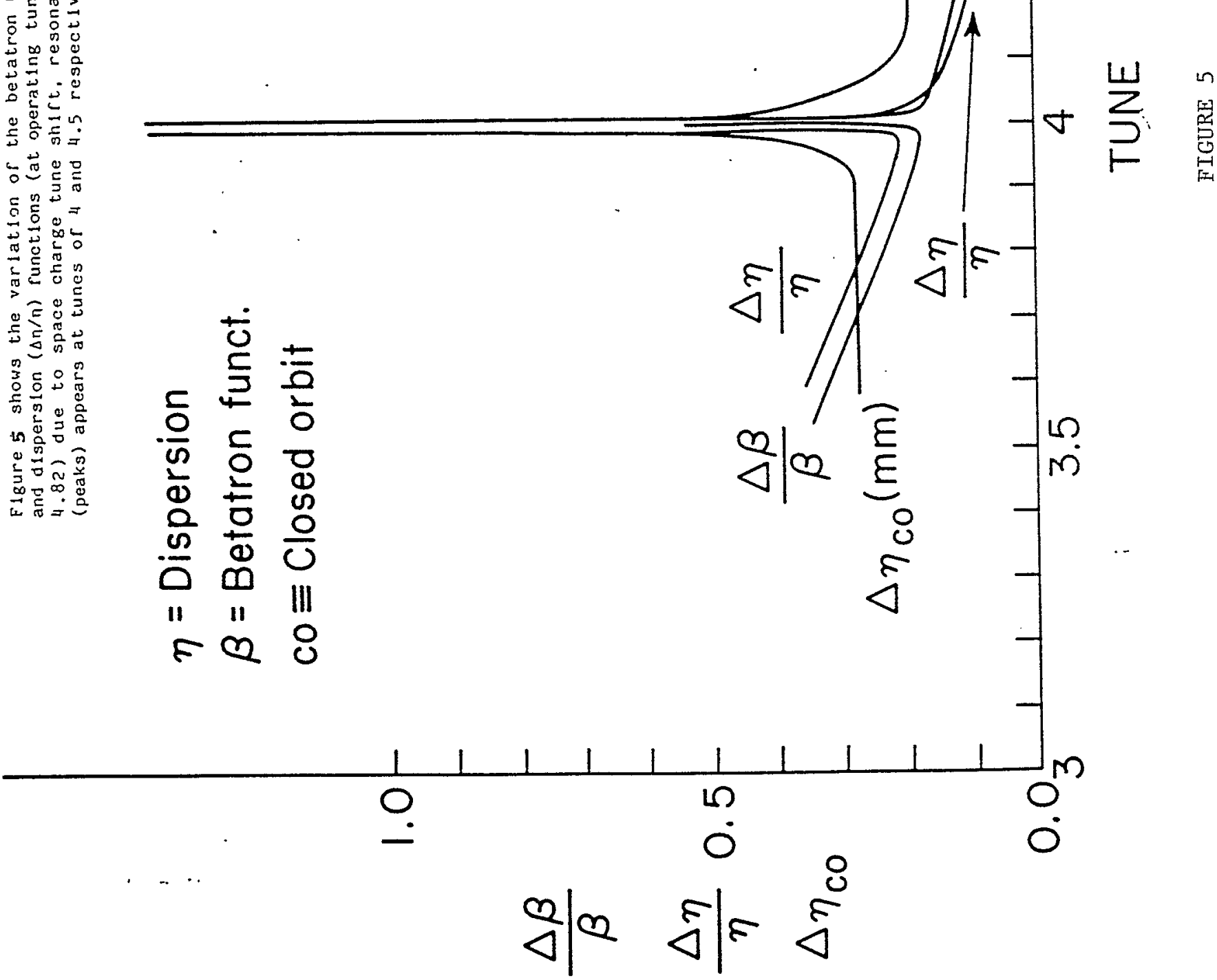


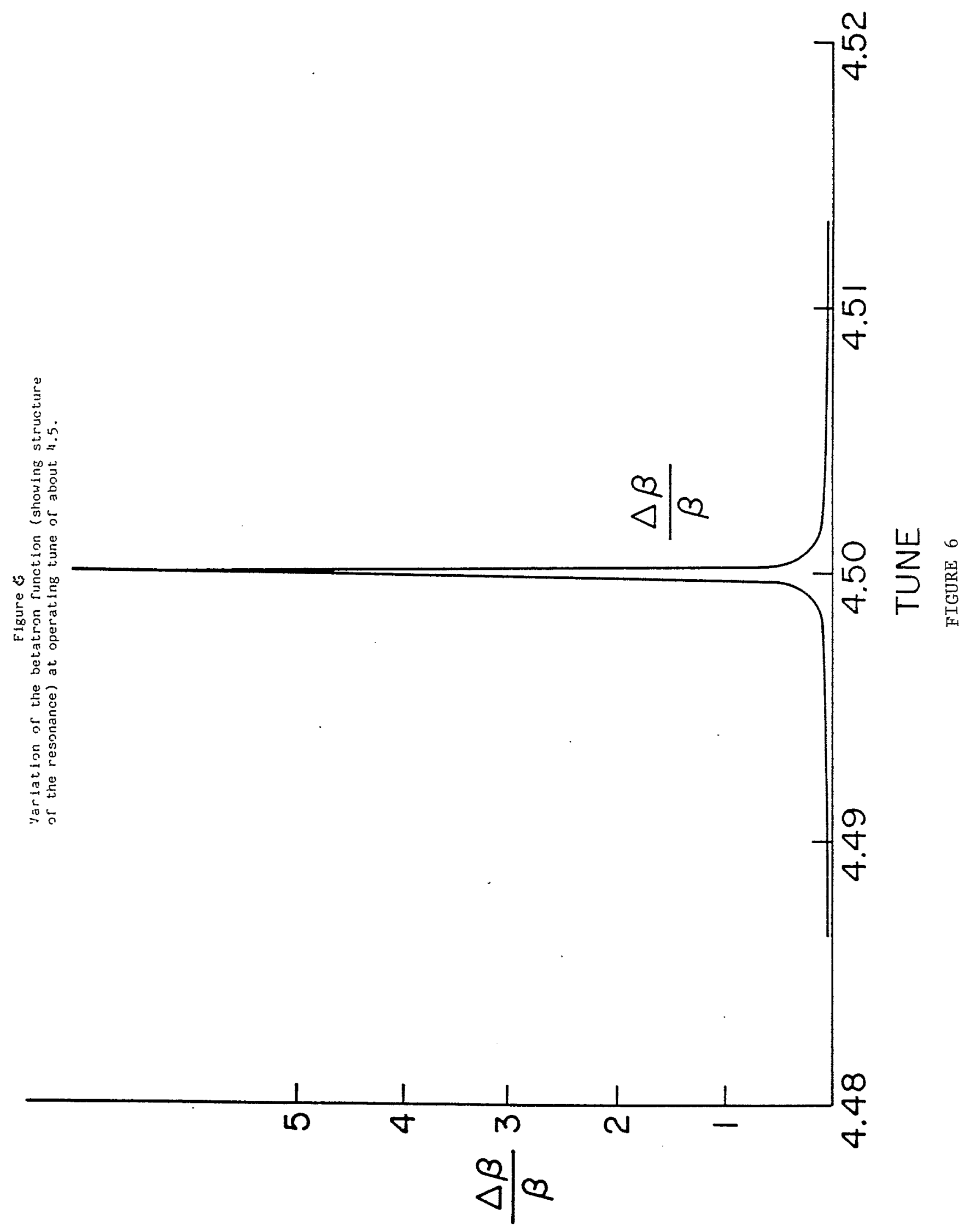




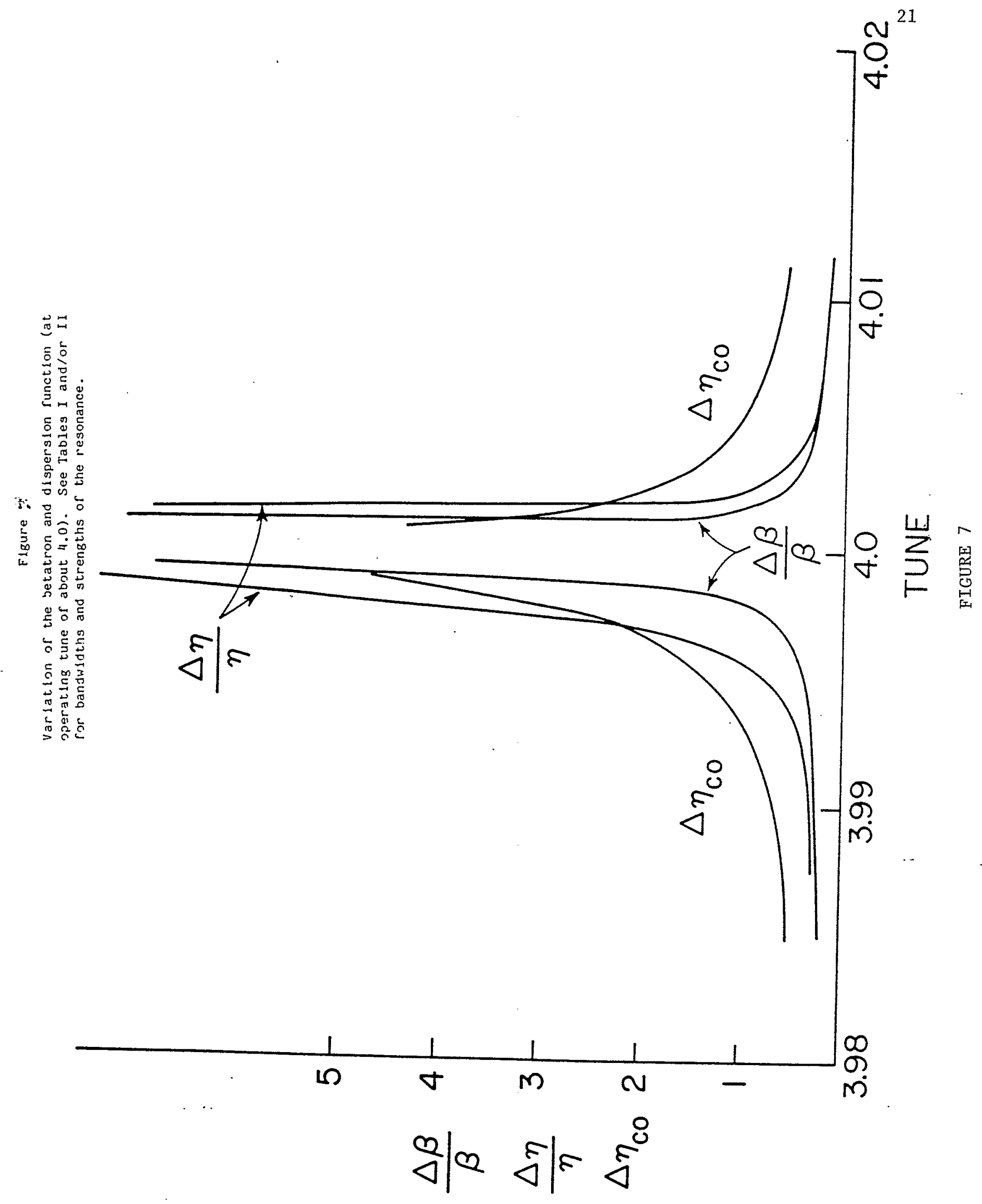




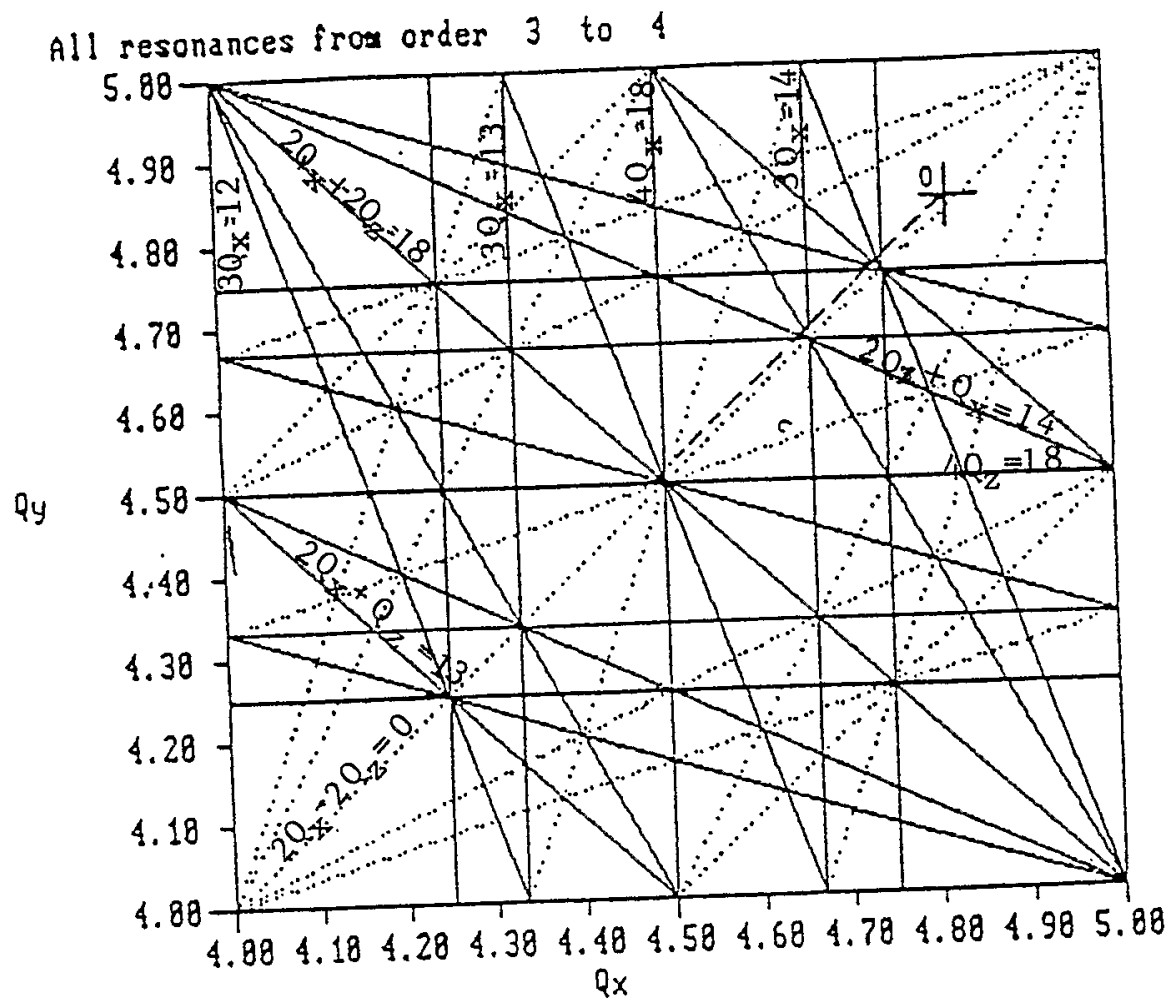

Figure shows the tune diagram and resonance lines for the Booster with operating point $0(4.82,4.83)$. The dashed line shows the expected region of tune shift due to the space charge. 

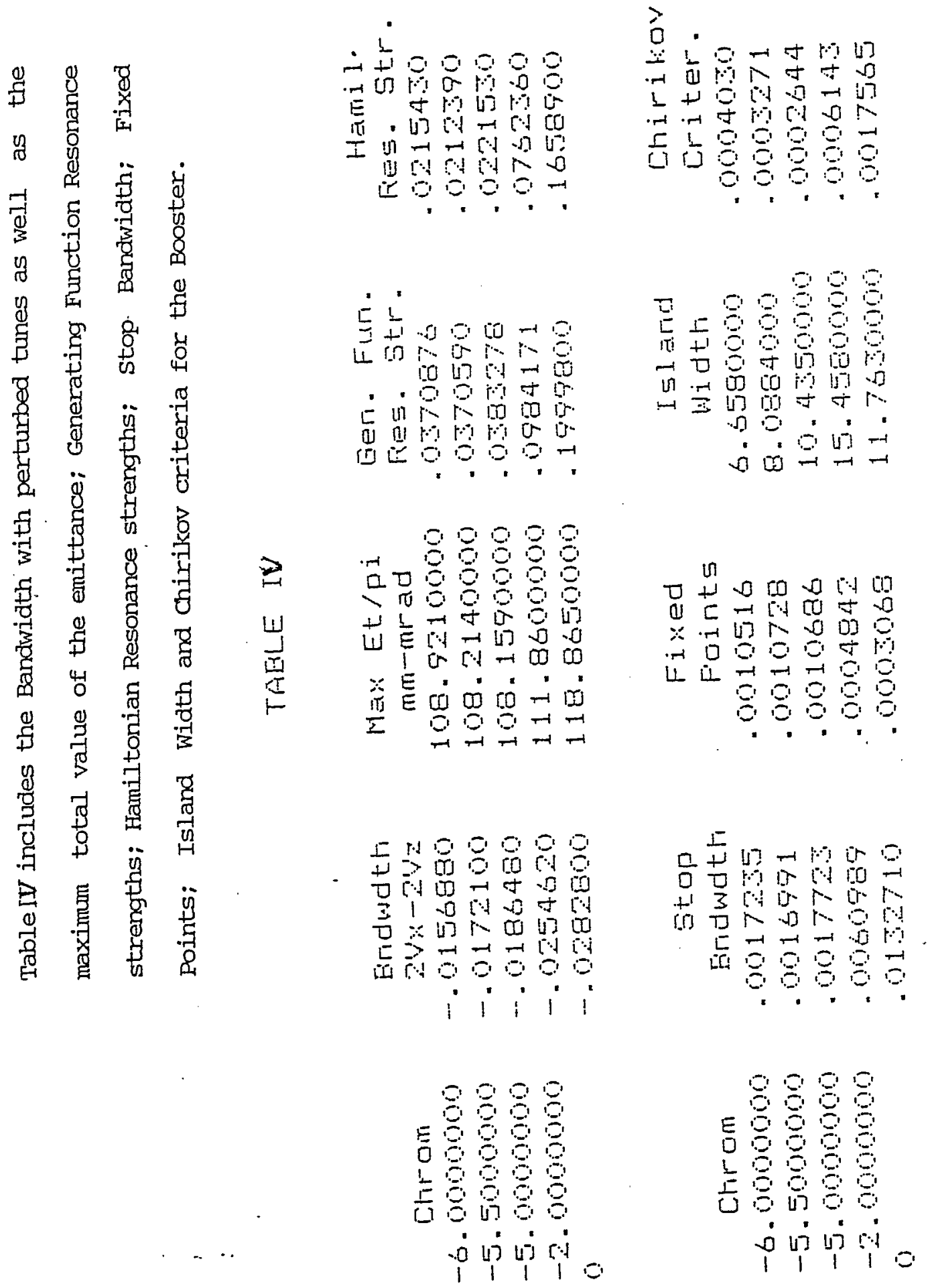


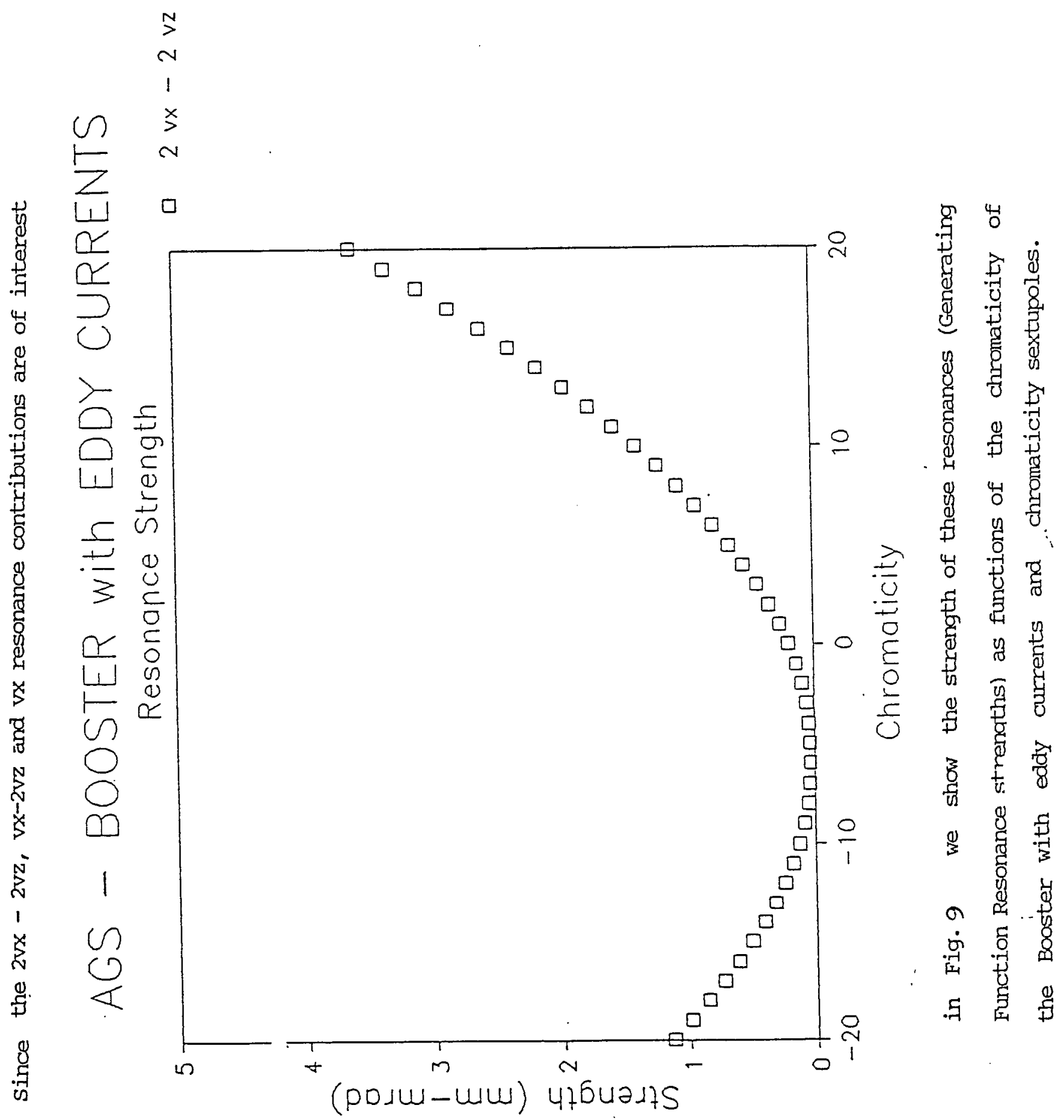




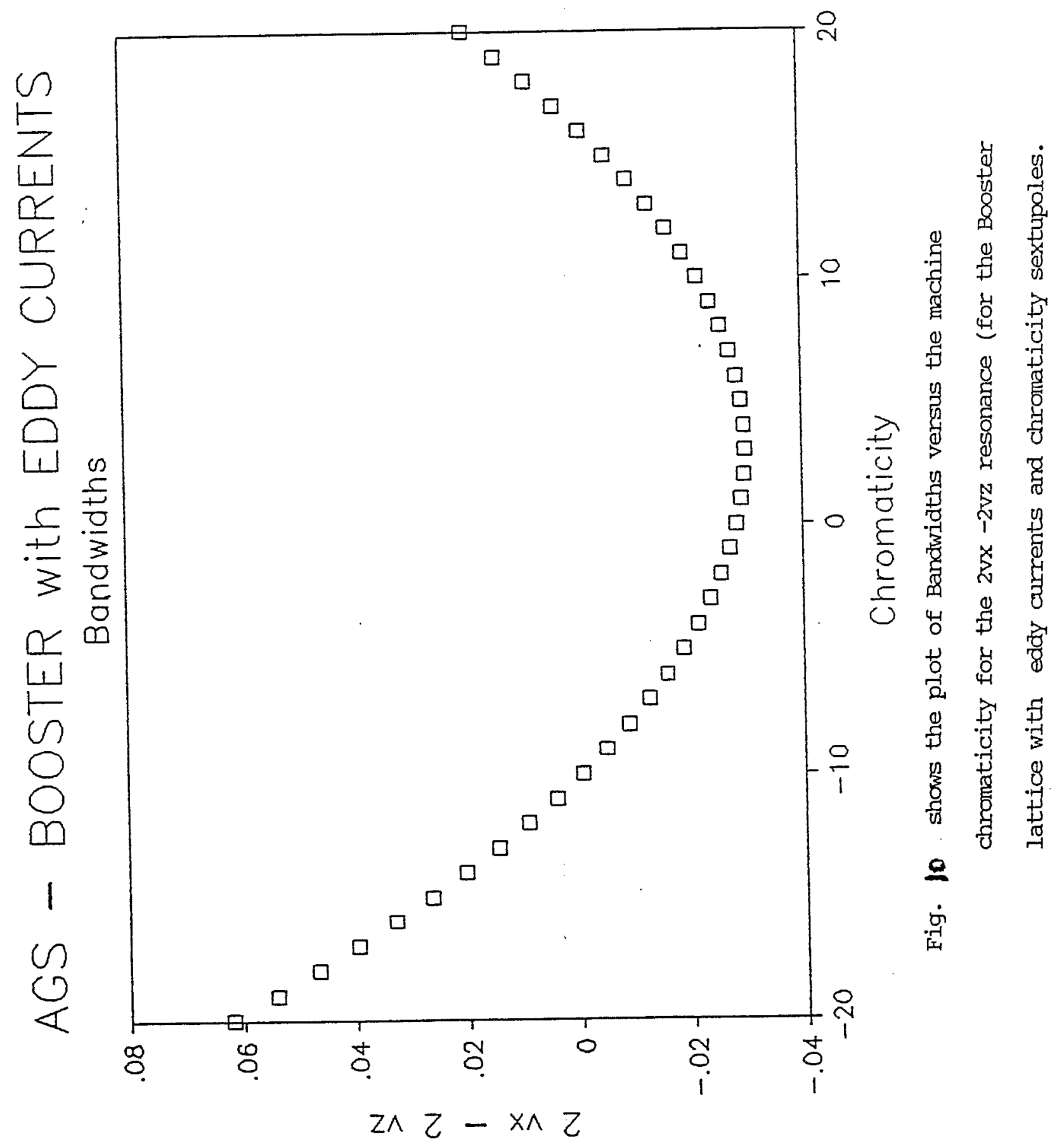




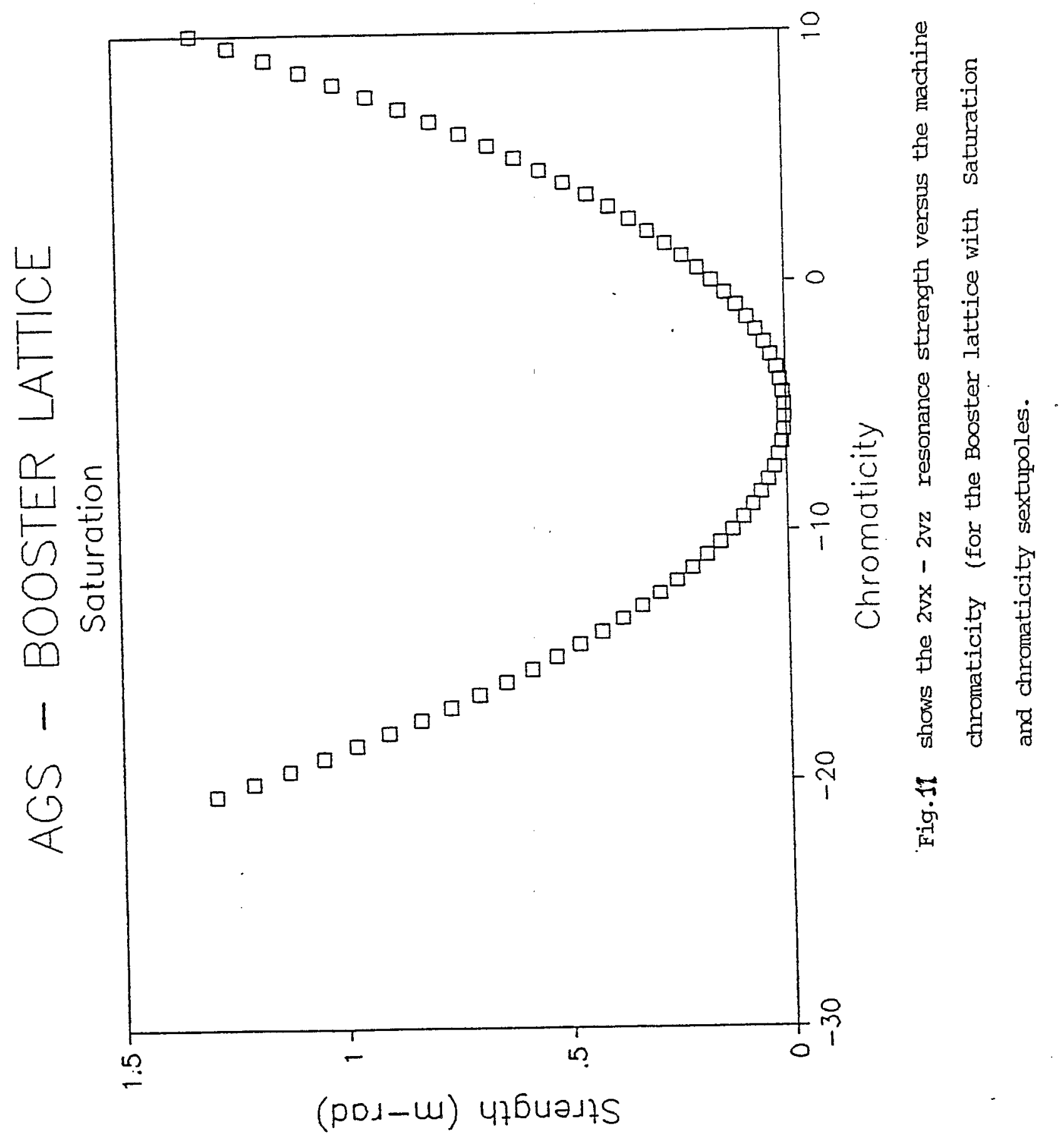




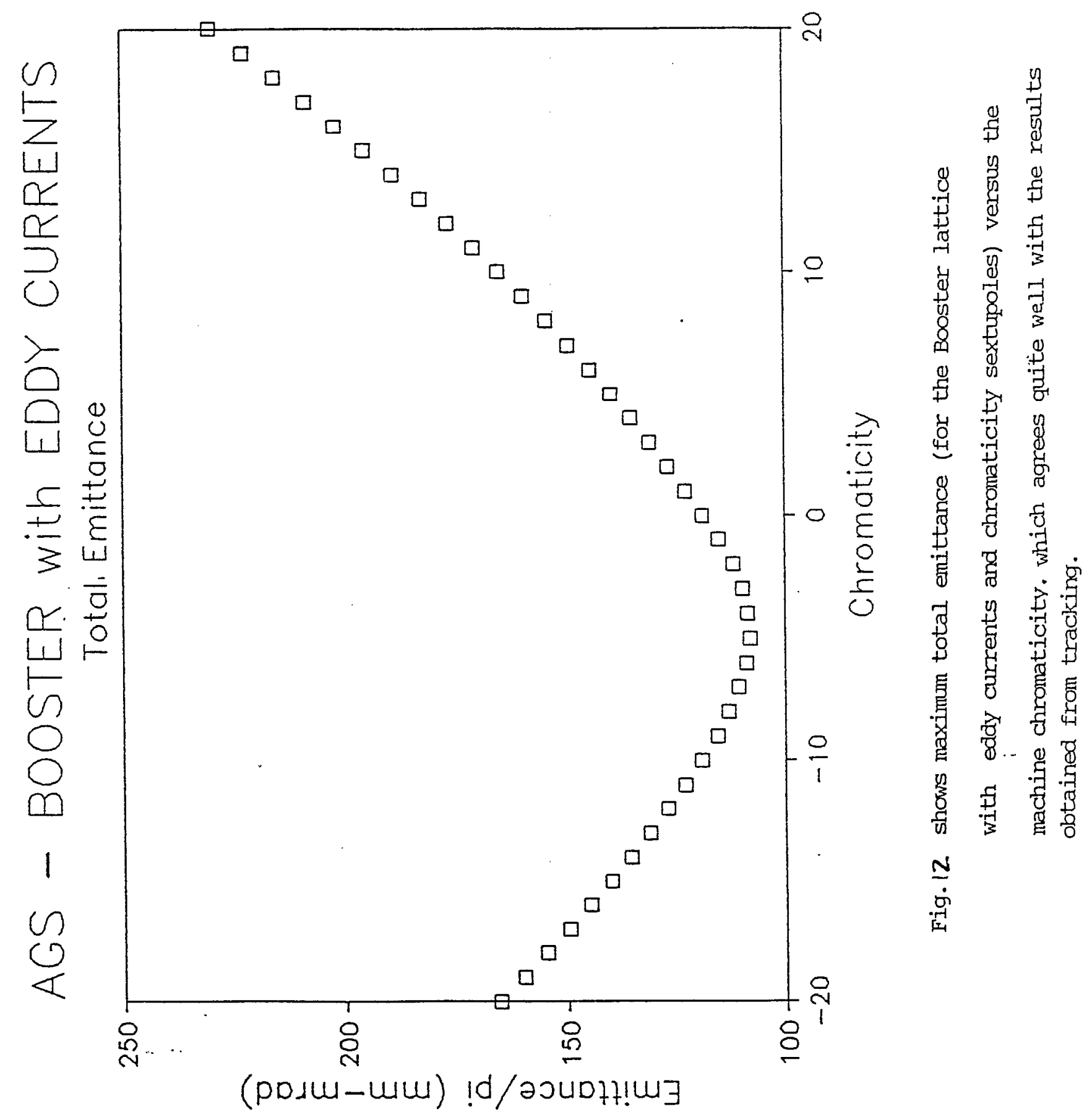




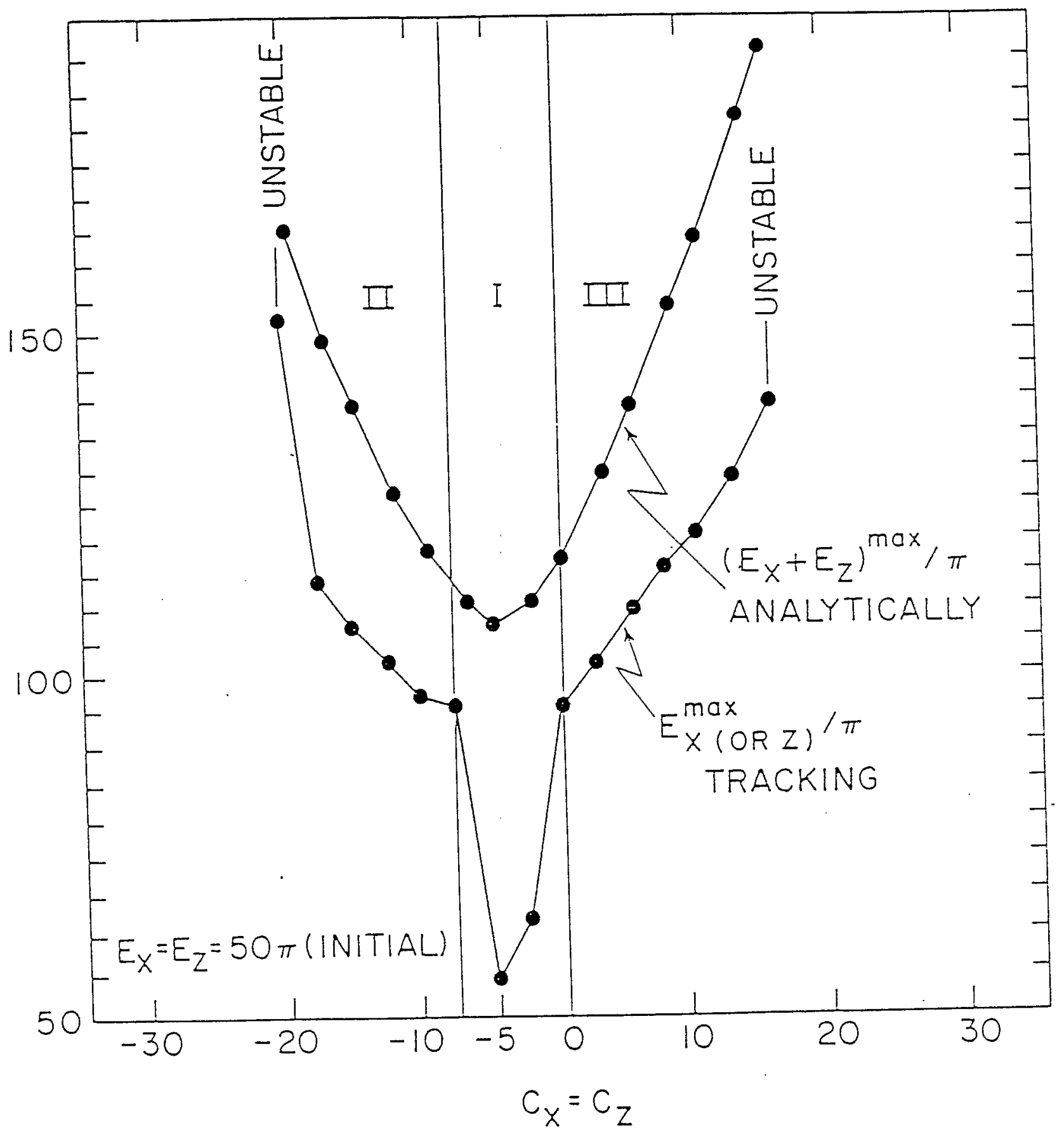

Fig. 13 shows the maximum emittance (in $x$ or $z$ direction) obtained from tracking 3 , and the maximum total emittance obtained analytically, as functions of the Booster chromaticity respectively. We note that one particle was used analytically and four particles were used in tracking. In region I, variation of the perturbed tunes (due to initial $\phi_{X}(s=0), \phi_{Z}(s=0)$ ) are small and do not cross the $2 v_{x}-2 v_{z}=0$ resonance for any particles. In region II and III, variation of the perturbed tune, (due to different initial phases $\phi_{X}(s=0)$ and $\phi_{Z}(s=0)$ ), becomes large, allowing the crossing of $2 v_{X}-2 v_{z}=0$ resonance for some of the particles. 
To relate our analytic result with those obtained from tracking we must relate the initial conditions. The initial conditions used for tracking are the phase $\phi_{X}(s=0)$ and emittance for the particle(s). However, the phase and the new actions $K_{\mathrm{X}}$ and $\mathrm{K}_{\mathrm{z}}$ are the parameters for the initial conditions in our analytic approach. These initial conditions can be related with the following expressions:

$$
\begin{aligned}
& E_{X}(s=0)=E_{X}\left(K_{X}, K_{Z}, \phi_{X}(s=0), \phi_{Z}(s=0)\right. \\
& E_{Z}(s=0)=E_{Z}\left(K_{Z}, K_{Z}, \phi_{X}(s=0), \phi_{Z}(s=0)\right.
\end{aligned}
$$

If there is a strong coupling term(s) in those expressions (e.z. $2 v_{x}-2 v_{z}$ for the Booster, then changing the initial phase $\phi_{X}$ and $\phi_{Z}$ (for different particle(s) but keeping the same initial emittance $\left(E_{X}, E_{Z}\right)$ will produce a large spread in $K_{X}$ and $K_{Z}$ which in turn results in a spread in the nonlinear tunes (for the particles) and the likelinood of $a$. particle crossing the coupling resonance.

However, in tracking several particles are used, the particle that gives the smallest bandwidth $\left(2 v_{X}-2 v_{z}\right)$ will lead to the greatest emittance growth due to the coupling; so many particles will excite the coupling resonance while (at the same time) many others would not. The number of particles that excite this resonance depends on how large are the coefficients $\alpha_{x x}, \alpha_{x z}, \alpha_{z}$ (see eq.12 \&.13) as well as how large is the $\left(2 v_{x}-2 v_{z}\right)$ resonance strength. Our analytic and tracking 5 results (both) indicates at chromaticities $C_{x}=C=-5$, 
both the a's and resonance strengths are minimum. (This is the region where chromaticity correcting sextupoles is minimum.) This point is 1llustrated in Fig. 13, which shows the maximum emittance (in $x$ or $z$ direction) obtained from tracking (of particles) and the maximum total emittance obtained analytically (for one particle), as functions of the Booster chromaticity respectively. In region $I$, the strength of the coupling resonance is weak and a's are small (hence variations of the perturbed tunes due to initial $\phi_{X}(s=0), \phi_{Z}(s=0)$ are small) thus no particle will cross the $\left(2 v_{X}-2 v_{Z}=0\right)$ coupling resonance as confirmed by tracking. However, in region II and III variations of the perturbed tunes (due to different initial phases $\phi_{X}(s=0)$ and $\phi_{Z}(s=0)$, becomes large, (since the as are large) and the spread in $K_{\mathrm{K}}$ and $\mathrm{K}_{\mathrm{Z}}$ is larger than in Region I (because the coupling resonance is larger) thus allowing the crossing of the coupling resonance for some particles. This can be seen from the analytic (one particle) and tracking (of four particles) plots in Fig. 13, where both methods predict the smallest contributions from nonlinearities at chromaticity of -5 for the Booster. 

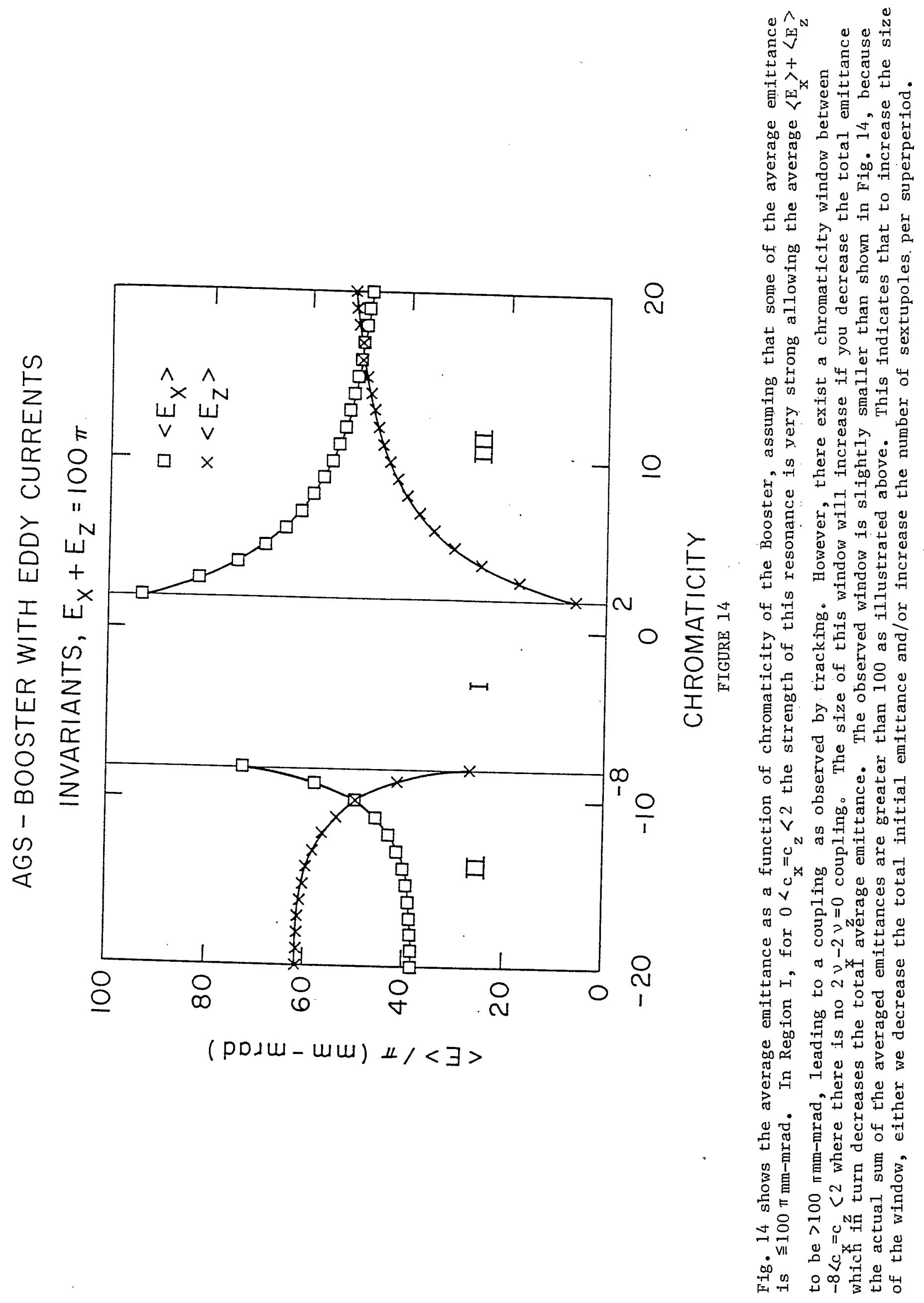


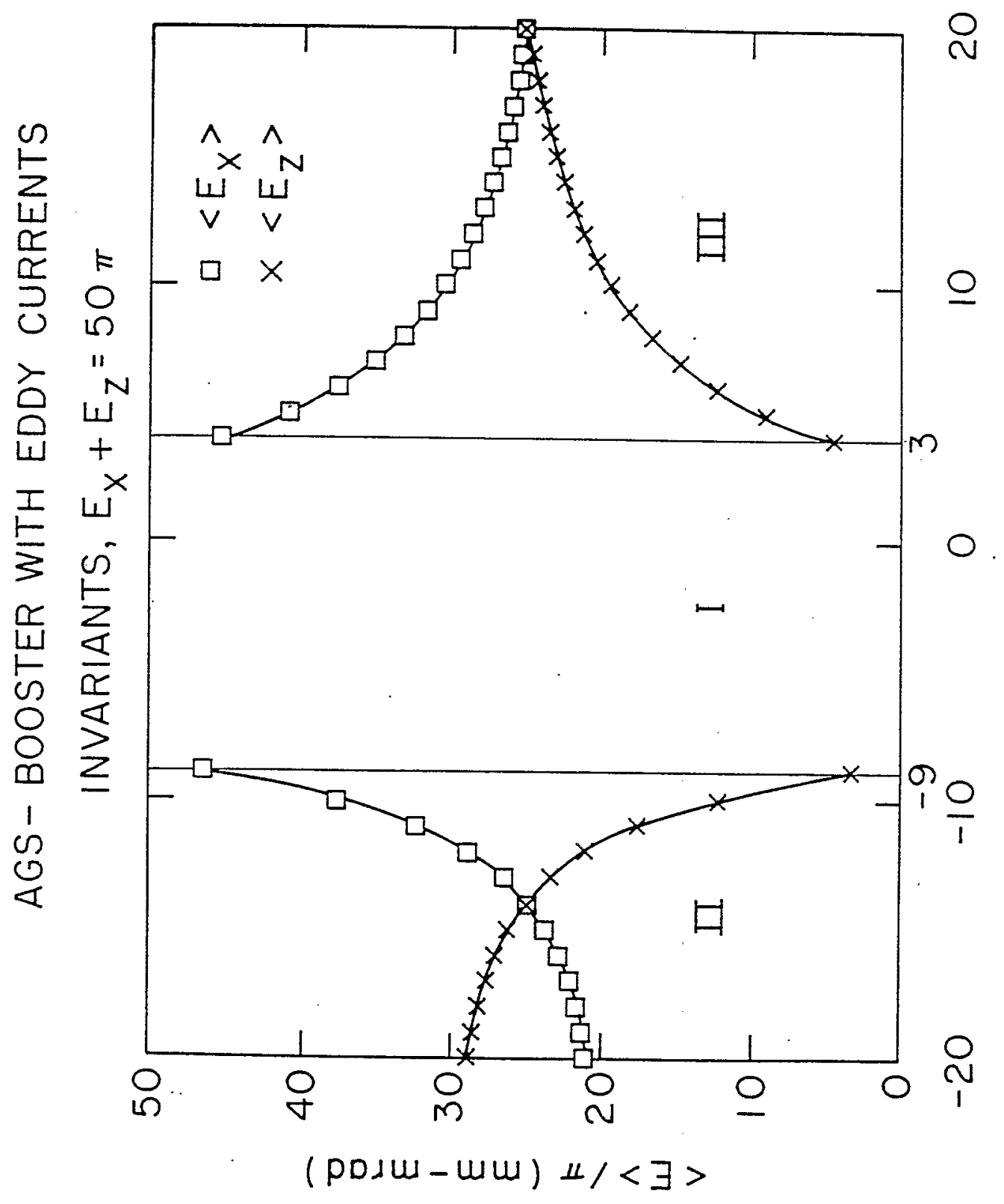

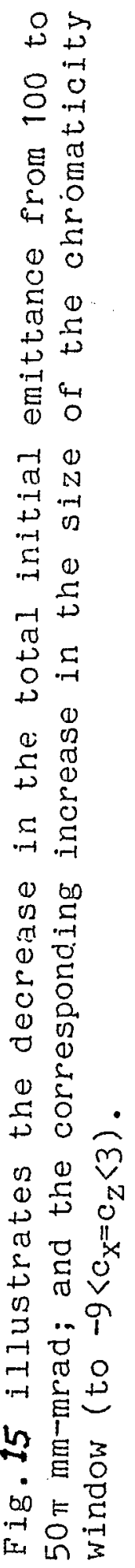


Figure 16 shows the plot of $\mathrm{E}_{\mathrm{Z}}^{1 / 2}$ versus $\mathrm{Ex}^{1 / 2}$ (for the Booster) where the emittance values were computed with the initaial conditions $\phi_{\mathrm{X}}=0, \phi_{\mathrm{Z}}=0$; $\mathrm{K}_{\mathrm{X}}=\mathrm{E}_{\mathrm{X}_{\mathrm{O}}} / 2 \pi$ and $\mathrm{K}_{\mathrm{Z}}=\mathrm{E}_{\mathrm{z}_{\mathrm{O}}} / 2 \pi$ at a given sextupole position. When the initial conditions are changed to the position of a different sextupole (multipole) the maximum values themittance grows to remains almost the same. Thus, no preference in the choice of initial tracking position. Given $\Psi_{X}$ and $\Psi_{Z}$, using equations $(9-10,14-17)$ we solve for $\phi_{X}$ and $\phi_{Z}$; then solve for $E_{X}$ and $E_{Z}$. The next point in the sequence is found by incrementing $\phi_{X}$ and $\phi_{z}$ by $2 \pi \nu_{x}$ and $2 \pi \nu_{z}$ which is the position of the same sextupole in the next revolution.

From our plots (e.g. Fig. 16) we can calculate "smear", "linear aperture" etc.

These type of plots contain the same information one would obtain from tracking program and can be used as alternative to tracking. That figure also illustrates the presence of strong coupling due to $2 v_{X}-2 v_{z}=0$ resonance which is indicated by the negative slope of the shaded area.

Similar observations have been made using tracking programs PATRICIA (F.DeII) and ORBIT (G.Parzen). 


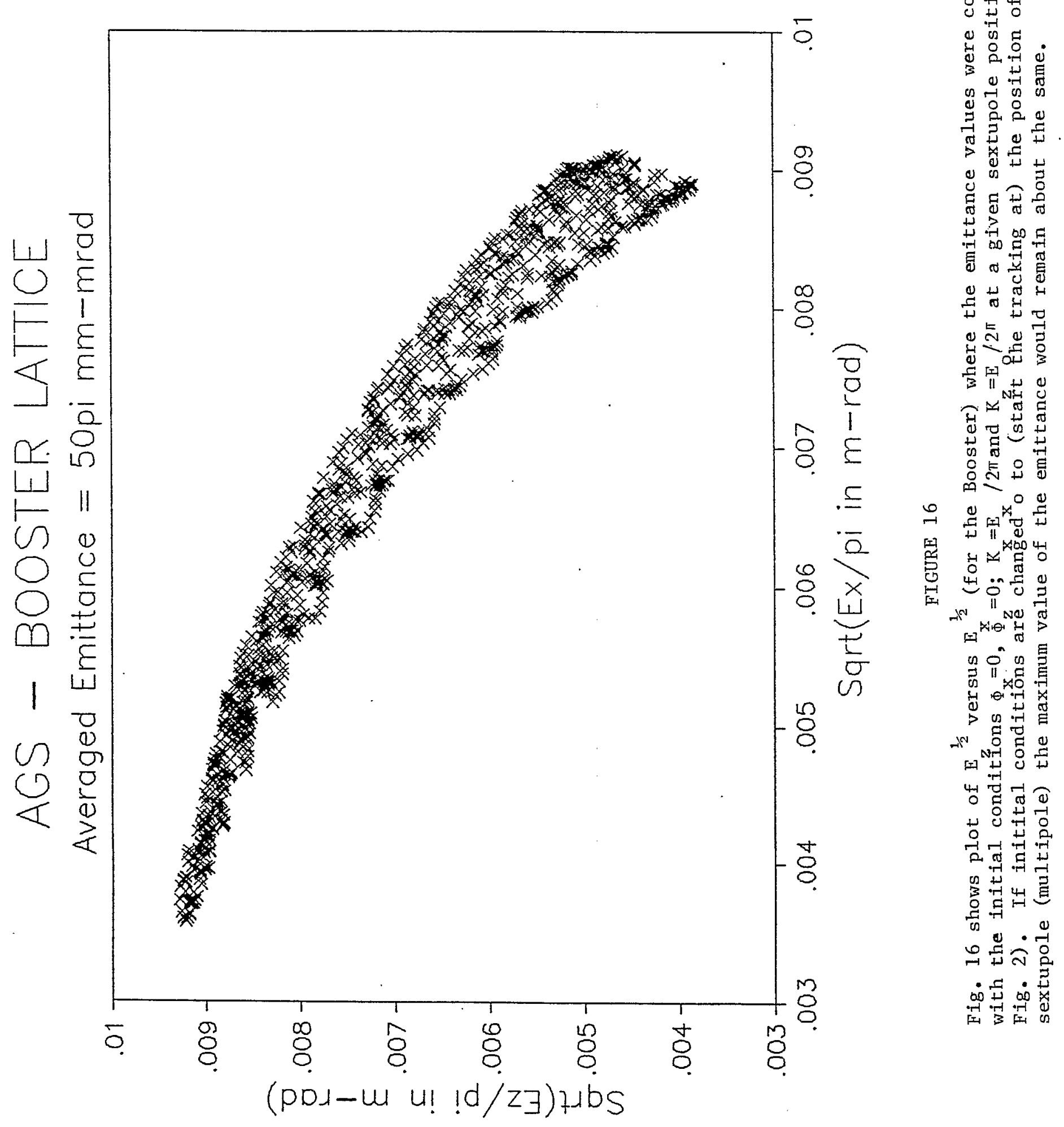




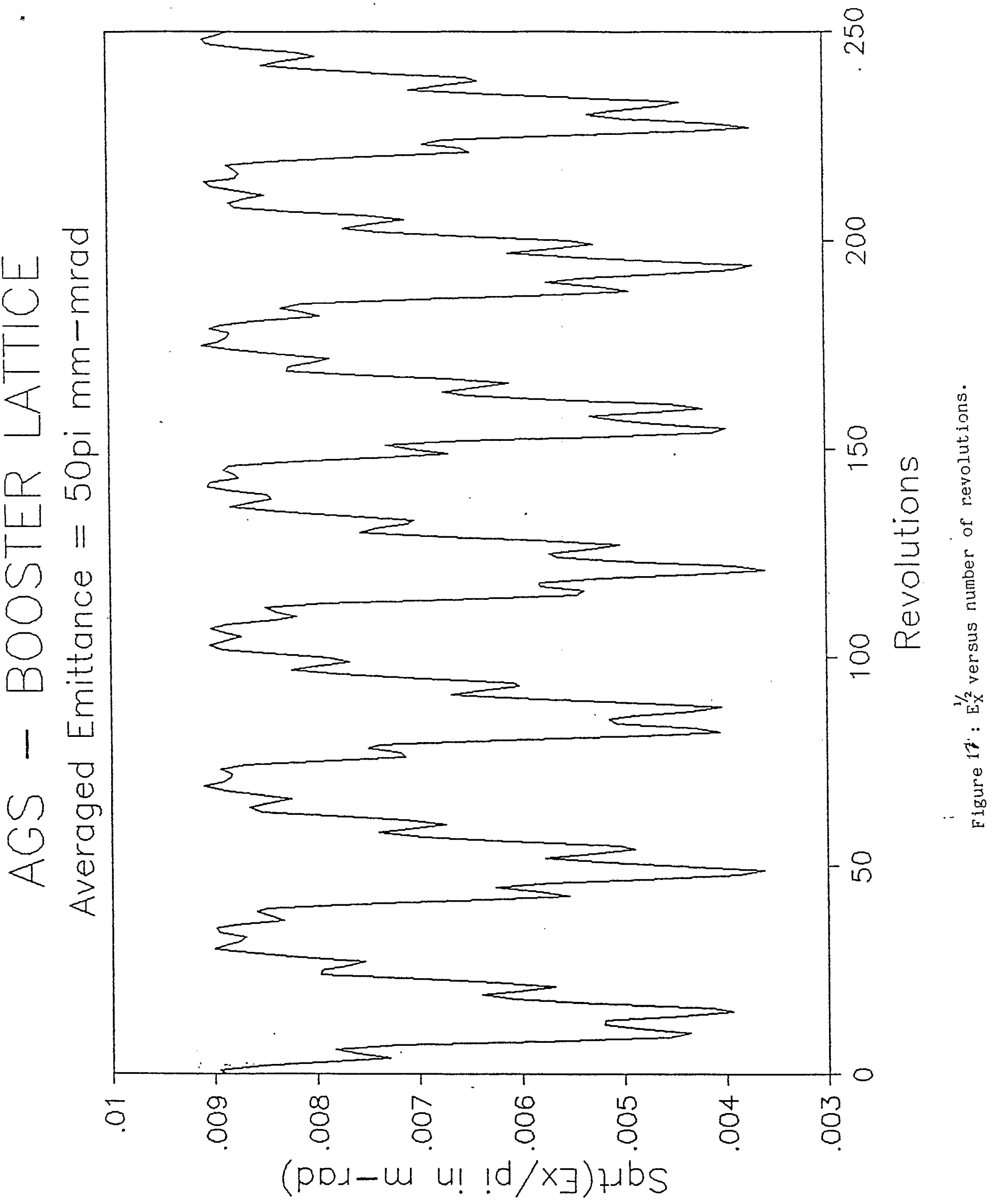




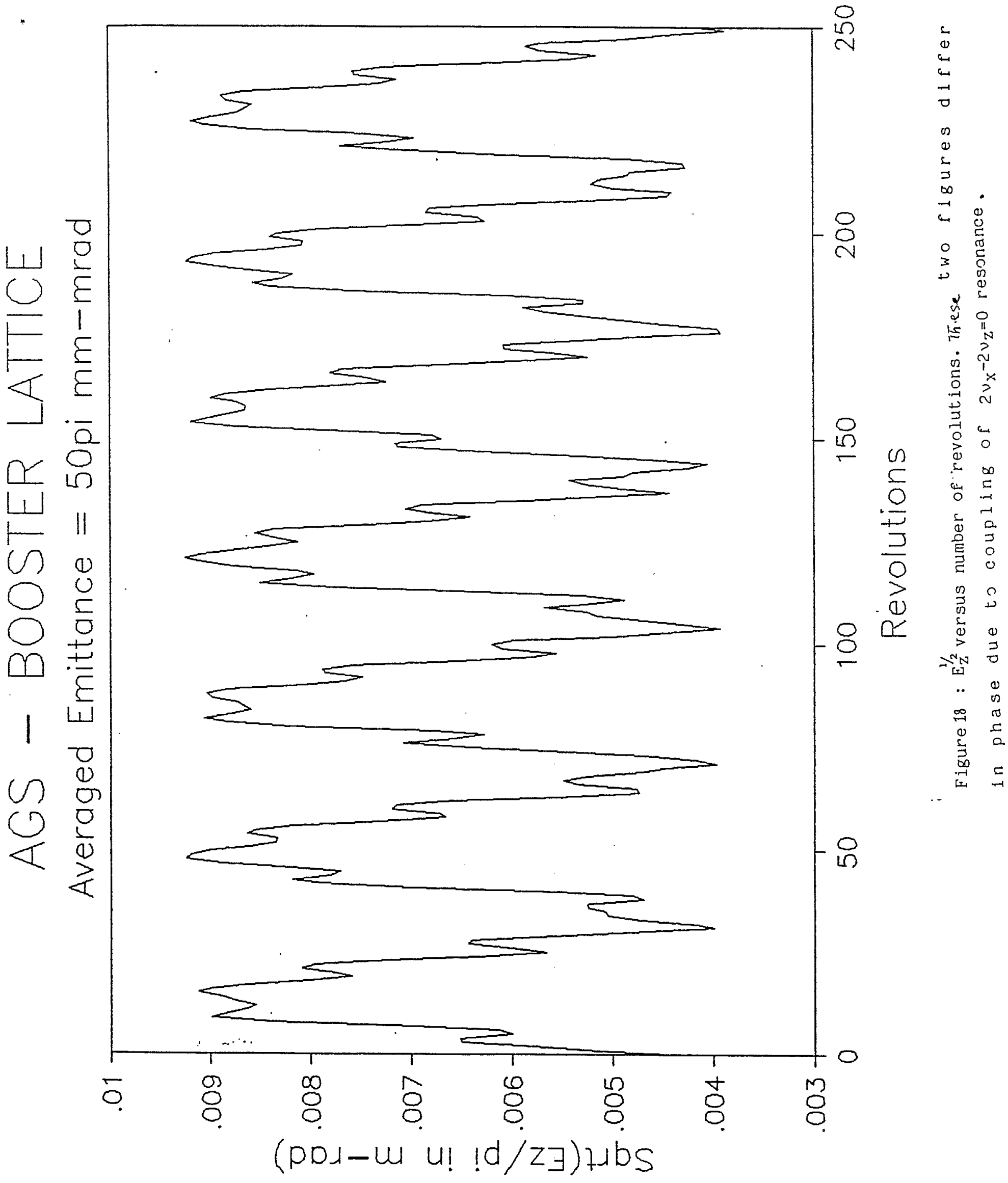




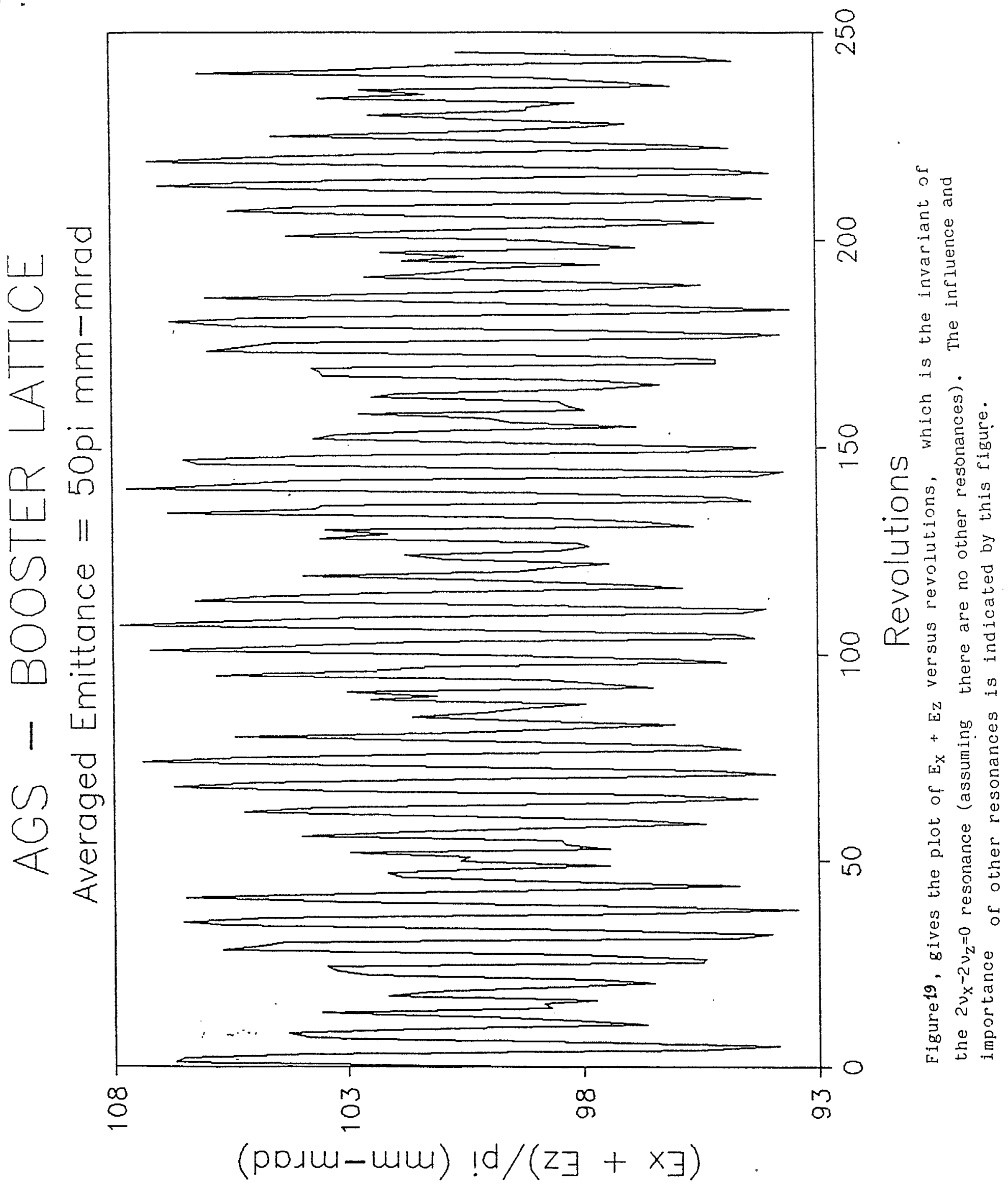




\section{Comparison of the phase}

plots, Figures 20 and 21 obtained analytically with Figures 22

and 23 (obtained from tracking ${ }^{5}$ ) indicates good agreement (e.g. for the maximum $x, \dot{x}$ and $z, \dot{z}$ ). However, the fine structures seen in Figures 20 and 21 are not apparent in Figures 2zand 23 due to slight differences in tune and the fact that the tracking plots have a coarser bin, that smears out fine structure. The width of the bands in these Figures indicates the amount of coupling (and varies with change in tune as seen by comparison of these figures). It becomes large when the chromaticity of the Booster is corrected to zero, indicated by our analytic and tracking results. 


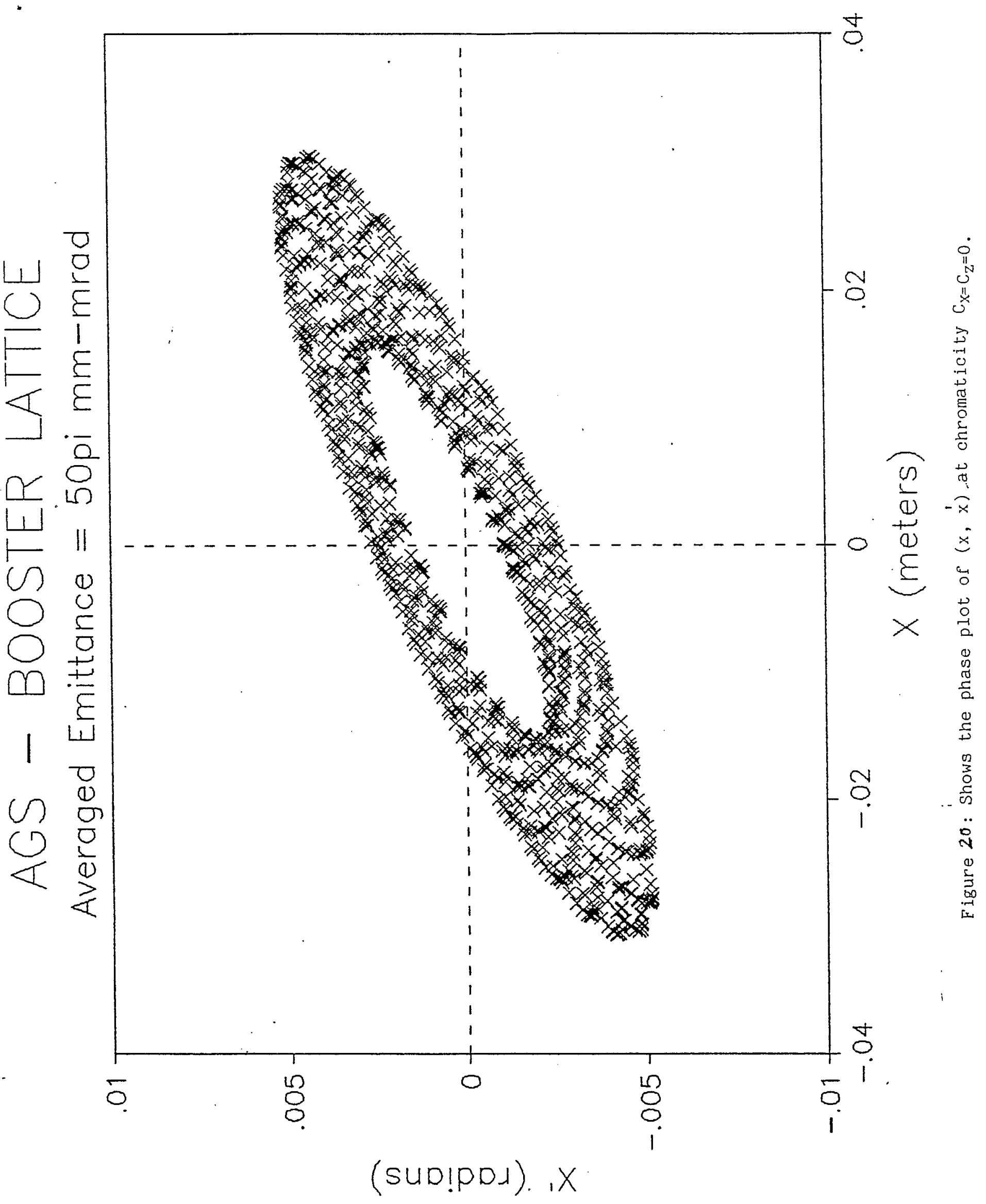


$N$

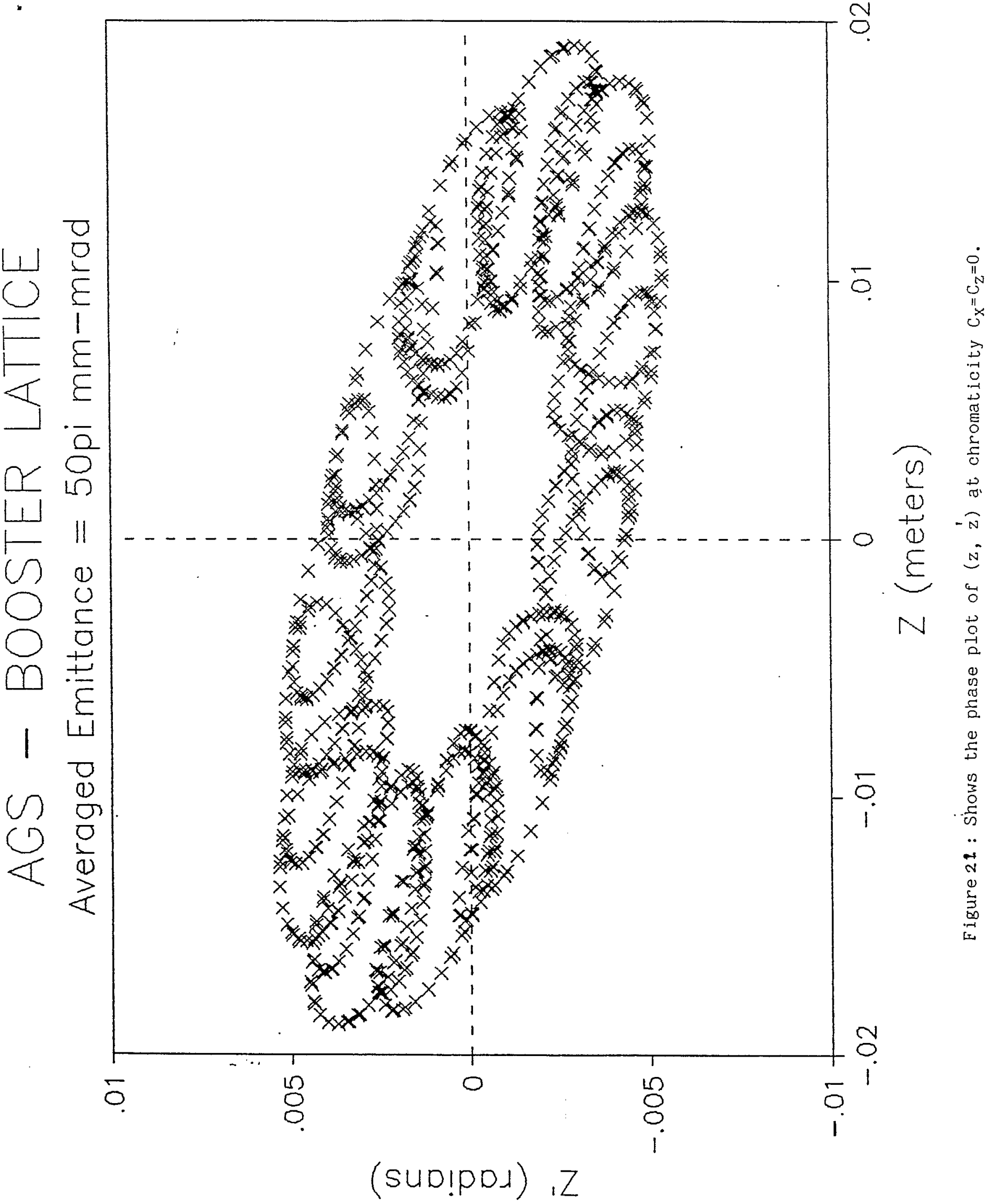




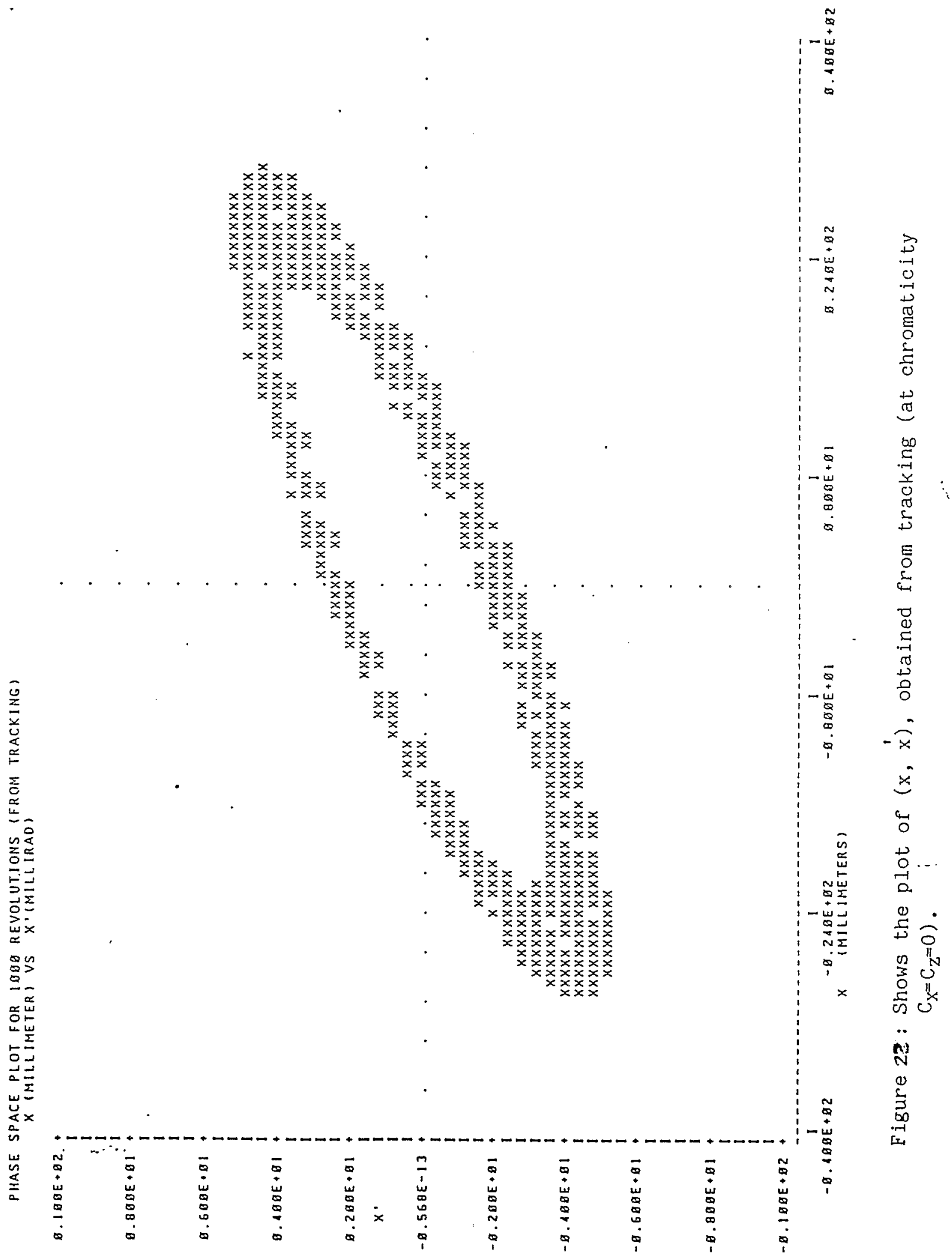




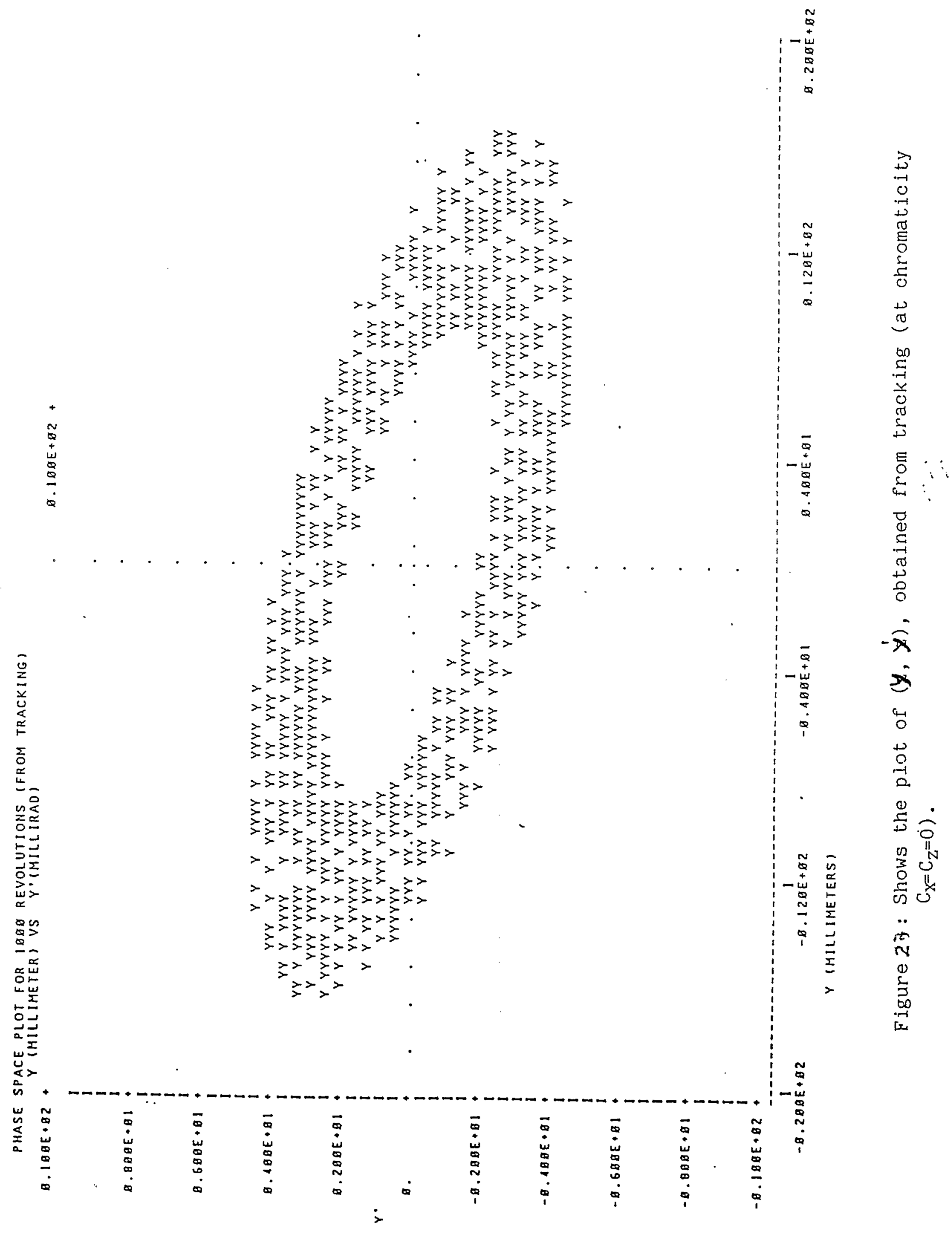




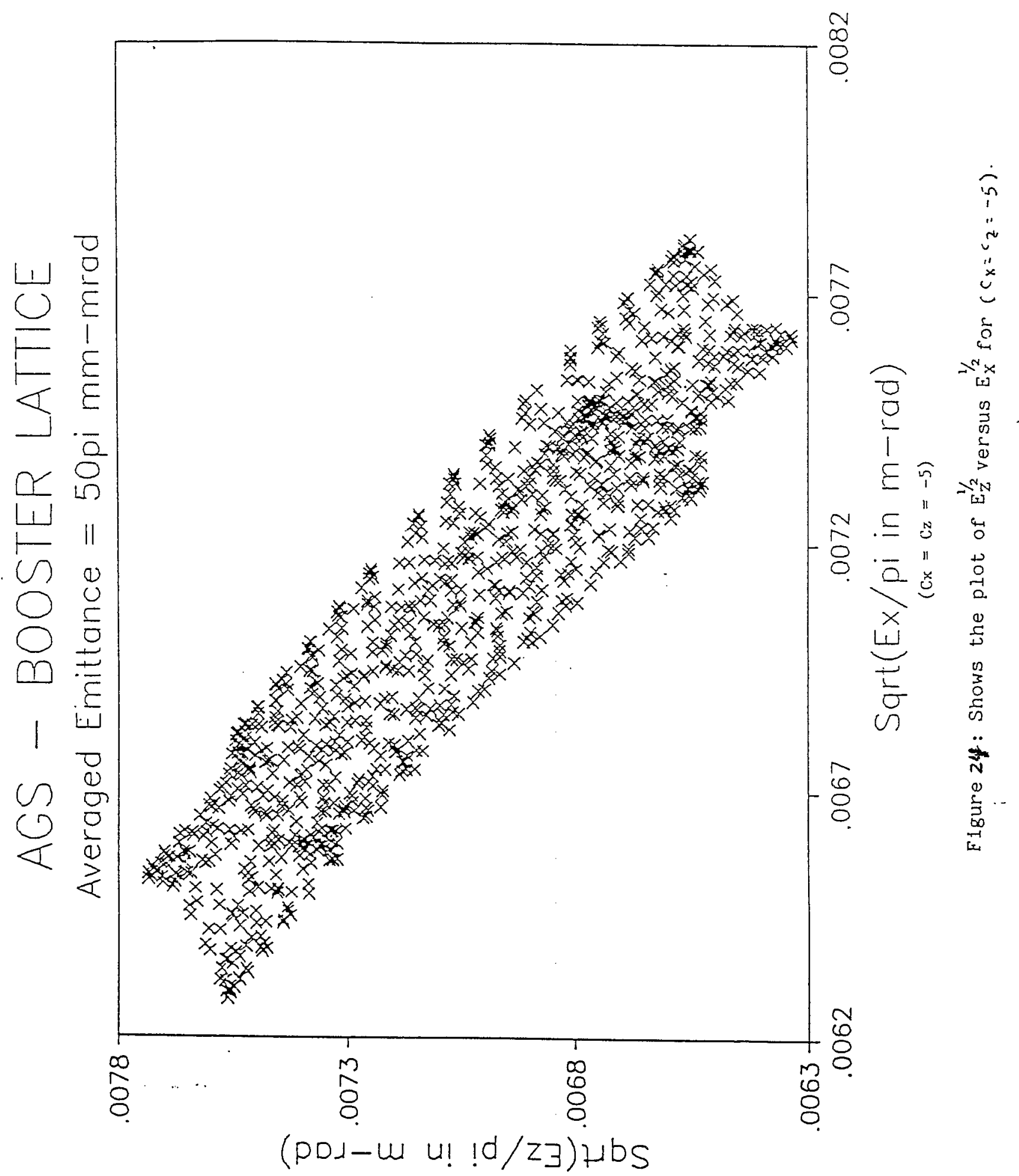


Furthermore, comparisons of Figures 25 and 26 (phase plots of $x, \dot{x}$ and $z, z^{\prime}$ respectively) which illustrates the reduction in the $\left(2 v_{X}-2 v_{z}\right)$ coupling at chromaticities $C_{X}=C_{Z}=-5$, with Figures $2 \bar{y}$ and 28 (obtained from tracking also with $\mathrm{C}_{\mathrm{K}}=\mathrm{C}_{z}=-5$ ) again shows good agreement between our analytic and tracking results. (Noting a slight tune difference in tracking.) 


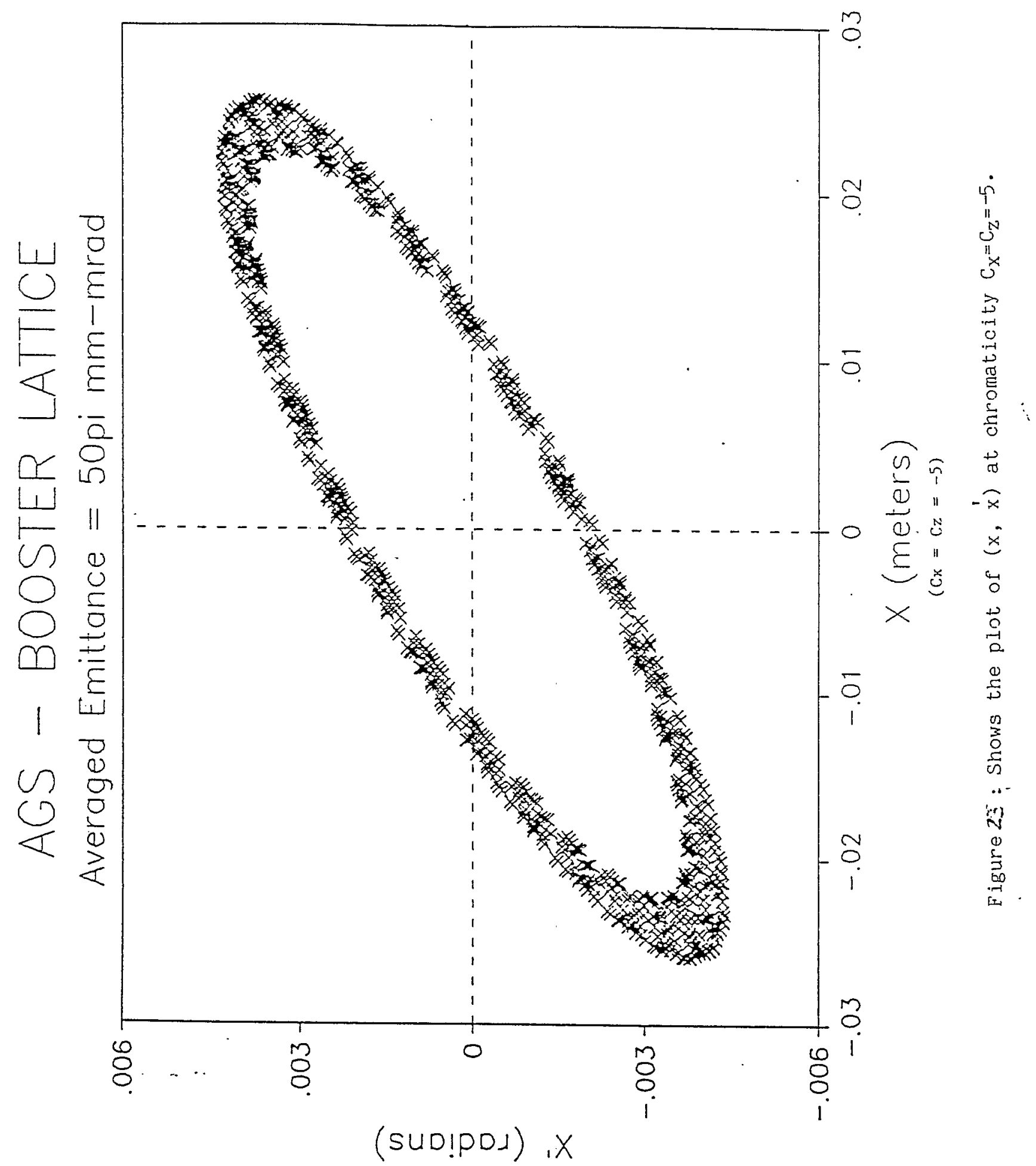




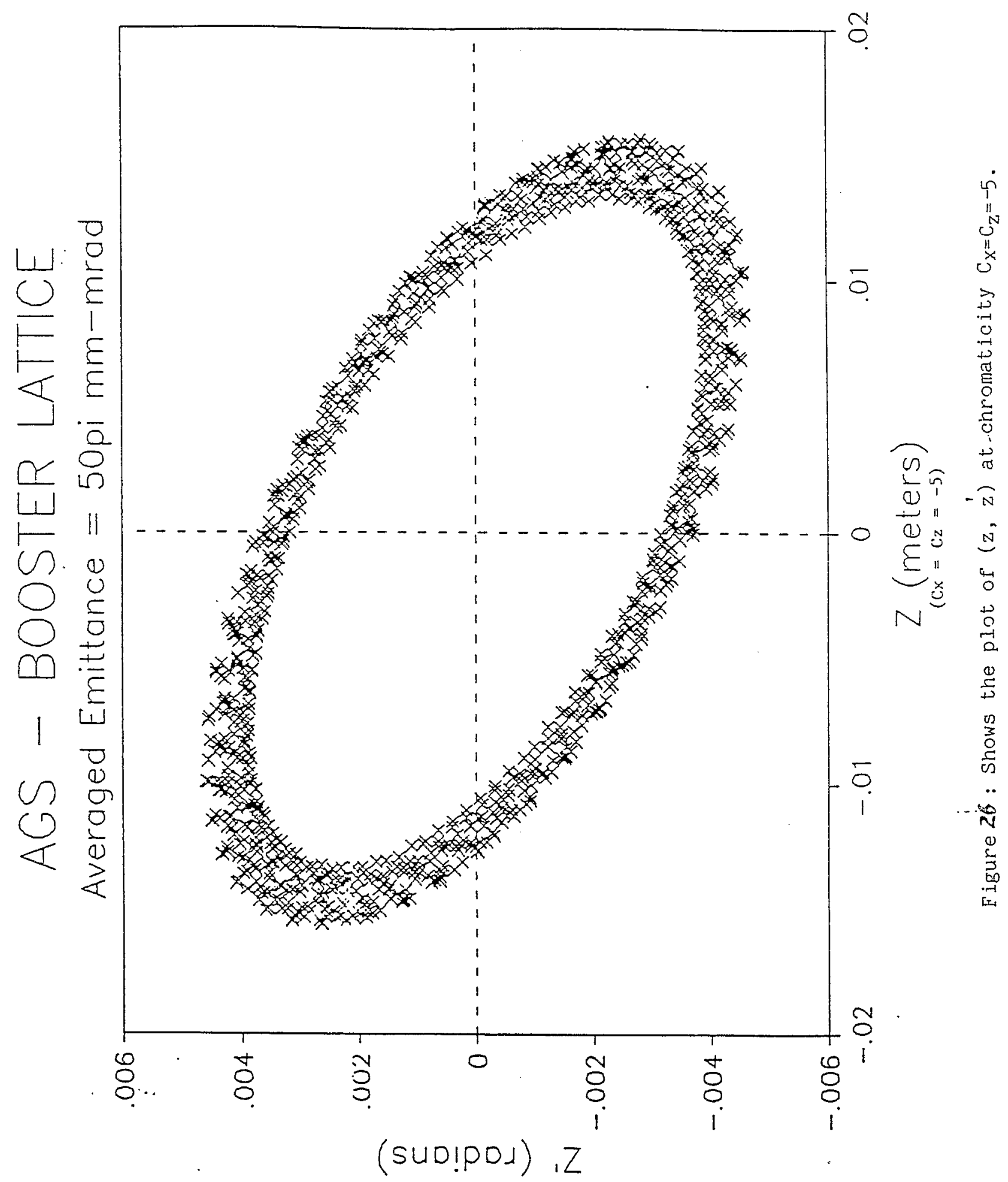




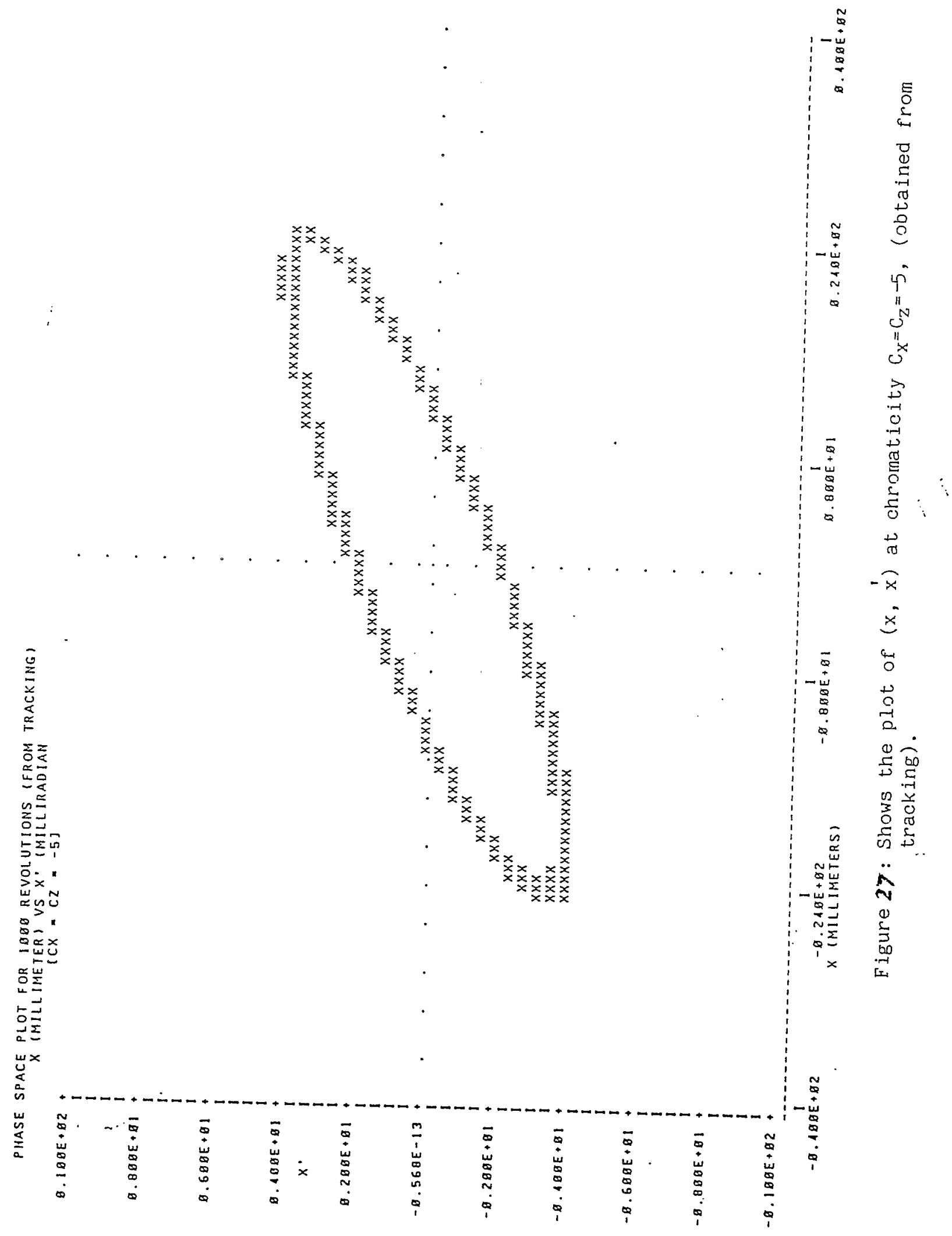




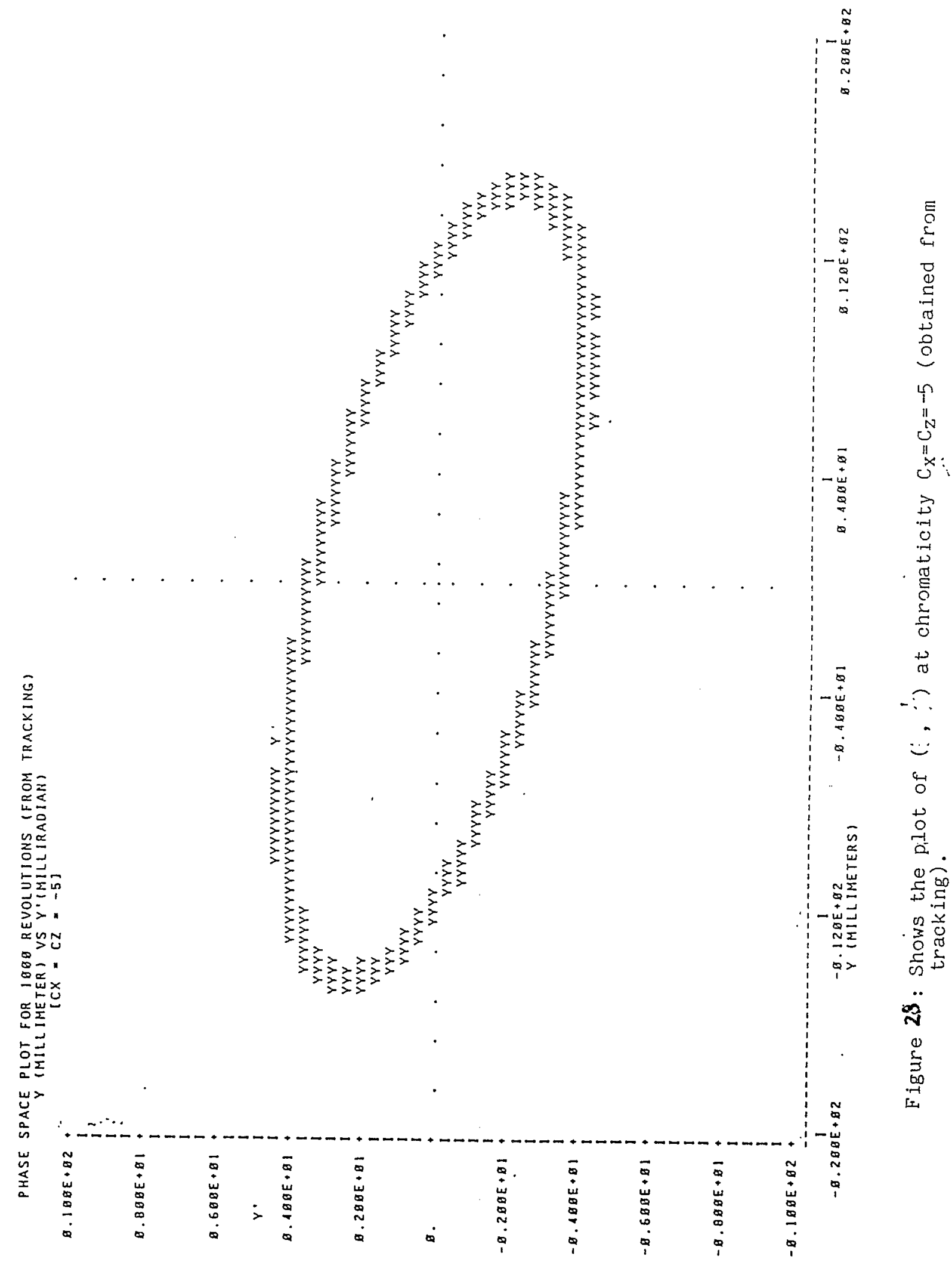




\section{CONCLUSION}

A large space charge tune shift in the AGS-Booster at injection, may cause the tunes to cross the fourth order structure resonances. If the space charge tune shift is large enough we may get near the third and sixth order resonances at tunes near 4.0. Tables I - III shows the perturbation to tunes and our results (e.g. stop bandwidths, resonance strengths for the third and fourth order resonances) obtained from NONLIN (Table II) and HARMON (Table III): Our analytic results agrees well with those obtained from tracking programs, if the initial conditions are considered. We note no preference for the choice of the initial tracking position. Since the maximum emittance growth will remain about the same regardless of the multipole position in the ring (Booster) from which we start the tracking. We also showed the existence of a chromaticity window for the Booster, where there is no $2 v_{X}-2 v_{z}$ coupling. The size of the window would increase if either we decrease the total initial emittance and/or increase the number of the sextupoles per superperiod. 
References

1. Z. Parsa, S. Tepikian, E. Courant, Second Order Perturbation Theory for Accelerators, BNL -39262

2. Z. Parsa, Proceedings of IEEE March 15-19, 1987, BNL-39449, 39450, 39451 and Accelerator Dynamics and Beam Aperture, BNL-38977

3. M. Donald, D. Schofield, A Users Guide to the HARMON Program, Lep Note 420 (1982); M. Donald, Private Commuication.

4. Z. Parsa, Booster Parameter List, BNL-39311; and Booster Design Manual

5. F. Dell, Tracking with modified 1980 version PATRICIA, (BNL) (unpublished); G. Parzen, Tracking with ORBIT, (BNL) (unpublished). The tracking results obtaned by Dell and Parzen agreed qualitatively; F. Dell, private communication; H. Wiedemann, Chromaticity Correction in Large Storage Rings, PEP Note 220 (1976); H. Wiedemann, User's Guide for PATRICIA, PEP Tech. memo PTM-230 (1981); S. Tepikian, private communication.

6. Z. Parsa, S. Tepikian, Beam Behaviour Studies in Accelerators with Perturbation Theory, BNL-39454 (submitted to Particle Accelerator Journal) 


\section{T.N. DISTRIBUIION}

BIDG. 911
AD Iibrary
(H. Martin)
G. Bunce
R. Casey
H. Foelsche
J. Grisoli
P. Hughes ( 1 ) + for each author
D. Lazarus
D. Iowenstein
T. Sluyters
W. Weng

FOR SSC PAPERS

ENAL

W. Fowler

P. Mantsch

$\underline{I B I}$
R. Donaldson (2)
W. Gilbert
V. Karpenko
P. Limon
K. Mirk
C. Taylor
M. Tigner

BIDG. 902

D. Brown

J.G. Cottingham

P. Dahl

M. Garber

A. Ghosh

C. Goodzeit

A. Greene

R. Gupta

J. Herrera

S. Kahn

E. Kelly

G. Morgan

A. Prodell

W. Sampson

R. Shutt

P. Thompson

P. Wanderer

E. Willen
BIDG. 460

N. Samios

BIDG. 510

H. Gordon

T. Kycia

I. Ieipuner

S. Iindenbaum

R. Palmer

M. Sakitt

M. Tannenbaum

I. Trueman
BLDG. 1005S

J. Claus

E. Courant

F. Dell

A. Flood

E. Forsyth

S. Y. Lee

Z. Parsa

G. Parzen

P. Reardon

S. Ruggiero

J. Sondericker

S. Tepekian

S\&P in Magnet Division for all MD papers

S\&P in Cryogenic Section for all Cryogenic Papers (and J. Briggs, R. Dagradi, H. Hildebrand, W. Kollmer)
BIDG. 725

H. Halama 